\title{
Covalently Templated Syntheses of Mechanically Interlocked Molecules
}

\author{
Milo D. Cornelissen \\ Simone Pilon \\ Jan H. van Maarseveen* \\ Van't Hoff Institute for Molecular Sciences, University of \\ Amsterdam, Science Park 904, 1098 XH Amsterdam, The \\ Netherlands \\ j.h.vanmaarseveen@uva.nl
}

This review is dedicated to the 70th birthday of Professor Ben L. Feringa
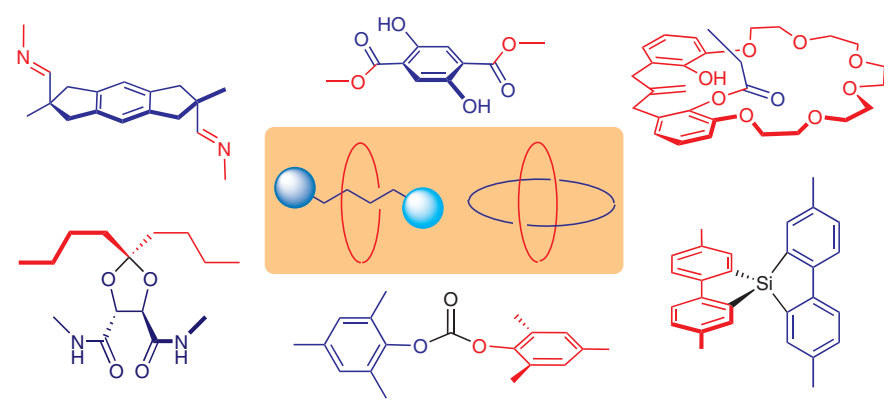

Received: 30.08 .2021

Accepted after revision: 17.09.2021

Published online: 08.10 .2021

DOI: 10.1055/a-1665-4650; Art ID: ss-2021-r0515-r

License terms: CCO

(c) 2021. The Author(s). This is an open access article published by Thieme under the terms of the Creative Commons Attribution-NonDerivative-NonCommercial-License, permitting copying and reproduction so long as the original work is given appropriate credit. Contents may not be used for commercial purposes or adapted, remixed, transformed or built upon. (https://creativecommons.org/licenses/by-nc-nd/4.0/)

Abstract Mechanically interlocked molecules (MiMs), such as catenanes and rotaxanes, exhibit unique properties due to the mechanical bond which unites their components. The translational and rotational freedom present in these compounds may be harnessed to create stimuli-responsive MiMs, which find potential application as artificial molecular machines. Mechanically interlocked structures such as lasso peptides have also been found in nature, making MiMs promising albeit elusive targets for drug discovery. Although the first syntheses of MiMs were based on covalent strategies, approaches based on non-covalent interactions rose to prominence thereafter and have remained dominant. Non-covalent strategies are generally short and efficient, but do require particular structural motifs which are difficult to alter. In a covalent approach, MiMs can be more easily modified while the components may have increased rotational and translational freedom. Both approaches have complementary merits and combining the unmatched efficiency of non-covalent approaches with the scope of covalent syntheses may open up vast opportunities. In this review, recent covalently templated syntheses of MiMs are discussed to show their complementarity and anticipate future developments in this field.

1 Introduction

2 Tetrahedral Templates

2.1 A Carbonate Template for Non-Rusty Catenanes

2.2 All-Benzene Catenanes on a Silicon Template

2.3 Backfolding from Quaternary Carbon

3 Planar Templates

3.1 Rotaxanes Constructed in a Ring

3.2 Hydrindacene as a Dynamic Covalent Template

3.3 Templating on Tri- and Tetrasubstituted Benzenes

4 Conclusion

Key words mechanically interlocked molecules, covalent template-directed synthesis, rotaxanes, catenanes, artificial molecular machines

\section{Introduction}

Few classes of compounds form such an alluring target to the synthetic chemist as mechanically interlocked molecules (MiMs). The intricate architectures of rotaxanes, catenanes, and knots are not only aesthetically pleasing, but exhibit unique properties by virtue of the mechanical bond which unites their components. ${ }^{1}$ The translational and rotational freedom granted by the mechanical bond gives rise to confined molecular motion. If this motion is harnessed within stimuli-responsive MiMs, ${ }^{2}$ far-reaching applications can be envisioned at the nanoscale. These artificial molecular machines could revolutionize fields such as drug delivery, sensing, and catalysis, but their full-fledged realization still awaits further advancements in synthetic methodology. ${ }^{3}$ In addition, MiMs are found in nature in the form of lasso peptides, ${ }^{4}$ as well as entangled proteins and DNA containing catenane structures, ${ }^{5,6}$ making them elusive targets for drug discovery.

The first directed [2]catenane synthesis by Schill in 1964 followed a covalent approach, ${ }^{7}$ which he greatly expanded in the following decades to find access to a range of rotaxanes, ${ }^{8}$ and higher-order catenanes. ${ }^{9}$ The influence of his pioneering research on contemporary covalent template-directed syntheses, but also supramolecular approaches, cannot be overstated..$^{10}$ After Sauvage achieved a metal-templated synthesis of a [2]catenane in $1983,{ }^{11}$ approaches based on non-covalent interactions quickly rose to prominence. A number of sophisticated methods have been reported over the years capitalizing on $\pi-\pi,{ }^{12} \mathrm{H}$-bonding, ${ }^{13}$ active metal ion, ${ }^{14}$ and crown ether-ammonium interactions, ${ }^{15}$ as well as newer approaches based on radical and halogen bond templating. ${ }^{16,17}$ The advantages of such strategies are unmistakable as these syntheses are generally short and highly efficient. These methods do, however, require particular structural motifs which are retained in the final product. These motifs are also difficult to alter, since small structural variations may perturb the dynamic equilibria of association which constitute these syntheses. ${ }^{18}$ 
Although these disadvantages are in many contexts irrelevant and have been alleviated by the development of new methodologies such as stopper-exchange strategies, ${ }^{19}$ it is sometimes needed to synthesize MiMs consisting of noninteracting or heteroatom-free components with increased translational and rotational freedom. Moreover, it is beneficial to be able to easily modify the composition and geometry of interaction sites as it expedites development and optimization of responsive MiMs. In other words, both the composer and the components enjoy more freedom in a covalent approach: the interlocked compound is liberated from its preorganizing elements upon cleavage of the template, whereas the synthetic chemist can freely adjust the product without disturbing underlying equilibria.

It is important to note that we do not perceive one approach to be superior, but merely argue that covalent and non-covalent strategies have complementary merits. The development of artificial molecular machines, for instance, encompasses the attainment of a vast system of molecules capable of performing collective as well as cooperative action. ${ }^{20}$ Cooperativity is defined as intermolecular coupling of individual subunits, as for example seen during oxygenation of hemoglobin, ${ }^{21}$ and remains especially challenging to contrive. The adaptability of covalent approaches makes them well-suited for the study of such interaction sites, but their laboriousness impedes their use in large systems. Combining the unmatched efficiency of non-covalent approaches with the scope of covalent syntheses may open up vast opportunities. By analogy with the production of fabric, in which an interlocking network of threads is efficiently produced through mechanized weaving and then tailored to a specific end, the synergy of both approaches may progress the development of molecular machines. In this review, recent progress in covalently templated syntheses of MiMs is discussed to show their complementarity and anticipate future developments in this field.

\section{Tetrahedral Templates}

Crucial to formation of a mechanical bond is the positioning of precursors on (approximately) orthogonal axes, after which the components can be interlocked through ring closure or capping. Although precursors are not completely orthogonalized in a tetrahedral geometry, they are placed on perpendicular planes, which often proves sufficient. By exploiting rigidity or other modes of restraint, the precursors can be forced to interlock upon ring closure. This leads to the formation of prerotaxanes or precatenanes,

\section{Biographical Sketches}

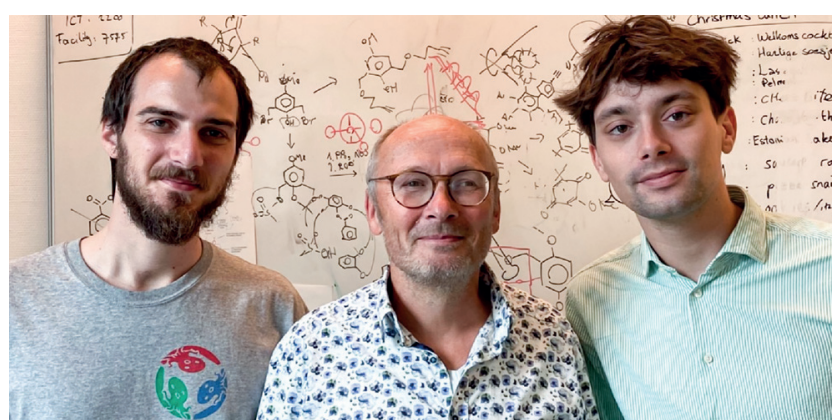

Jan van Maarseveen obtained his Ph.D. in 1994 at the University of Nijmegen on the total synthesis of antiviral indole alkaloids. From 1994-1999 he joined Solvay-Pharmaceuticals (Weesp, The Netherlands) as a pharmacochemist involved in combinatorial druglike molecule library synthesis and as a group leader in a traditional lead optimization program. In November 1999 he moved back to academia as an assistant professor at the University of Amsterdam. Meanwhile, he rose through the ranks and was promoted in 2015 to full professor. His background is the development of methodology to enable the synthesis of small and strained cyclic peptides together with the development of enantioselective catalytic methods with applications in alkaloid synthesis. Some years ago, the group shifted its research towards covalent scaffoldbased methodology development to synthetically disclose the natural lasso peptide series and other mechanically interlocked molecules. As a spin off, [n] rotaxanes are made for unidirectional electrons transport for applications in artificial photosynthesis. Jan is an enthusiastic teacher and obtained several prizes of which the 'best teacher of the year of the University of Amsterdam in 2012' award is the most prestigious one. In 2016 he was awarded the Royal Dutch Chemical Society Van Marum Medal for his contributions to chemistry outreach and excellence in teaching.
Simone Pilon obtained his B.Sc. at the Universitá degli Studi di Genova (Italy) after which he completed his M.Sc. at the joint chemistry programme of the University of Amsterdam and the Vrije Universiteit Amsterdam (Cum Laude). Currently, he is in the final year of his Ph.D. in the Synthetic Organic Chemistry group within the Van't Hoff Institute of Molecular Sciences at the University of Amsterdam.

Milo Cornelissen obtained his B.Sc. at the Amsterdam University College (Summa Cum Laude) and now is attending the joint Master's in Chemistry programme of the University of Amsterdam and the Vrije Universiteit Amsterdam. 
whose components can be liberated by cleaving the temporary linkages to the template.

\subsection{A Carbonate Template for Non-Rusty Catenanes}

In search of mechanically interlocked polymers, Godt synthesized a so-called 'non-rusty' catenane of which the rings lack mutual interactions. ${ }^{22}$ The higher degree of translational freedom of such catenanes makes them interesting targets for polymerization as it may increase their elasticity and impact resistance. In contrast to the common non-covalent methods to preorganize the ring precursors (e.g., metal-coordination, hydrogen bonding, $\pi-\pi$ stacking), Godt used a covalent carbonate linkage as the template to interlock two otherwise non-complexing rings. The method was later optimized as shown in Scheme $1,{ }^{23,24}$ giving access to differently sized and functionalized catenanes.
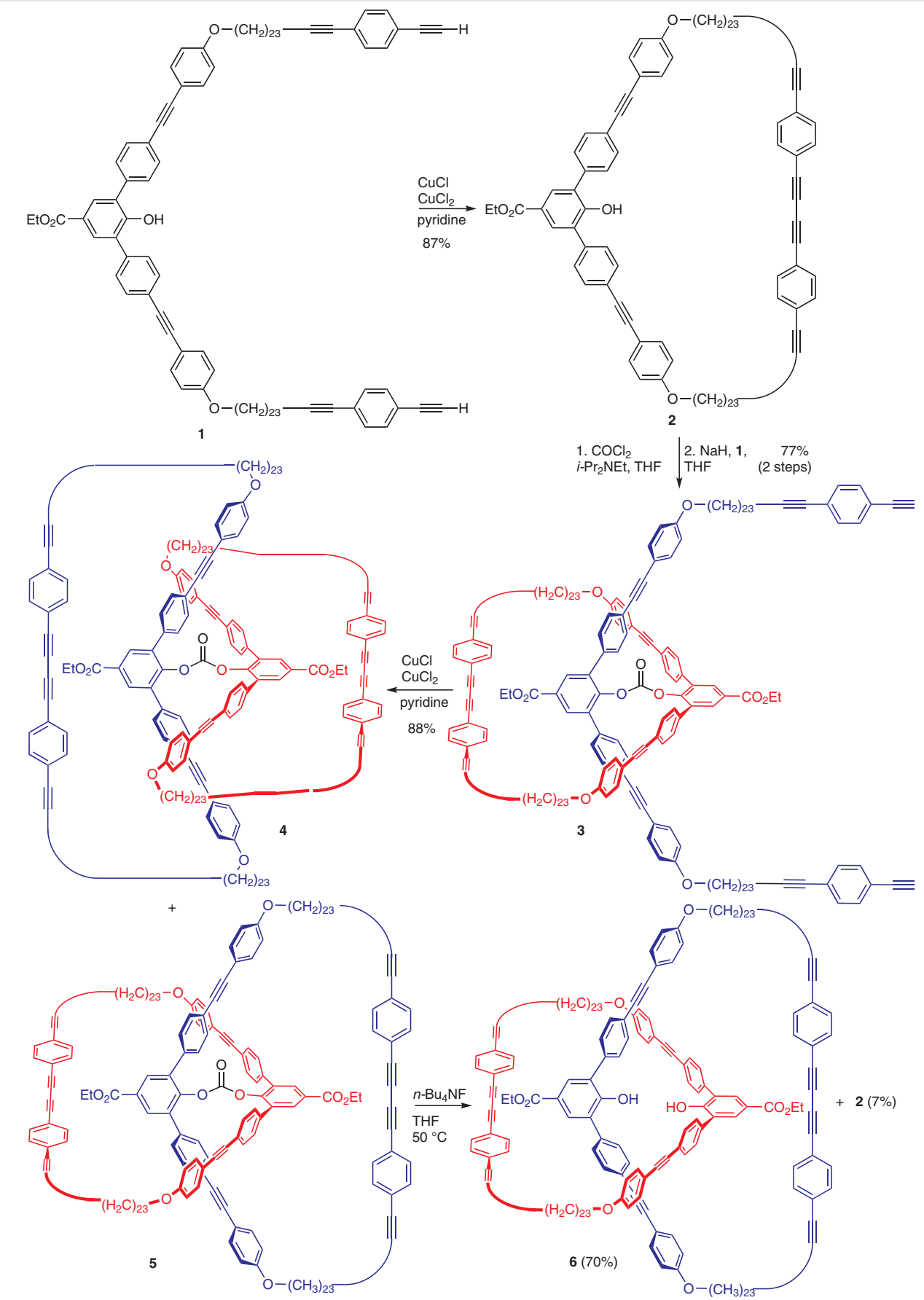

Scheme 1 Godt's synthesis of catenane 6 using a carbonate template 23,24,26 
The method was based on the notion that carbonates with rigid $\mathrm{W}$-shaped substituents, such as 2,6-diaryl-substituted phenols, adopt a conformation in which the substituents are directed towards the corners of a distorted tetrahedron. ${ }^{22}$ The steric bulk of the extended substituents prevents rotation around the template, locking them on orthogonal axes. Sauvage and Dietrich-Buchecker had shown earlier in their synthesis of $\mathrm{Cu}(\mathrm{I})$-phenanthroline templated catenanes that such preorganization can be highly fruitful, ${ }^{25,11}$ inspiring Godt to develop a related but covalent approach with wider scope in structure and functionalization. To ensure the efficient formation of large rings, cyclization was performed through oxidative dimerization of alkynes. Model studies showed that tolane groups were particularly stable under these conditions leading to the design of phenol 1 (Scheme 1), which was indeed cyclized in good yield to give 67-membered macrocycle $2 .{ }^{26}$ Phosgene was then added to ring $\mathbf{2}$, after which a reaction of the resulting aryl chloroformate with the sodium salt of phenol 1 yielded carbonate 3. Cyclization towards the 67-membered macrocycle under conditions of pseudo-high dilution then mainly gave precatenane $\mathbf{5}$, although some of the unthreaded isomer $\mathbf{4}$ formed as well. Separation of $\mathbf{4}$ and $\mathbf{5}$ proved difficult and therefore carbonate cleavage with $n-\mathrm{Bu}_{4} \mathrm{NF}$ was performed first. This enabled facile isolation of catenane $\mathbf{6}$, while the remains of $\mathbf{4}$ were obtained as the side product ring 2. Directly attaching two equivalents of ring precursor $\mathbf{1}$ to the carbonate template did not result in a precatenane, but instead led to dimerization of the $\mathrm{W}$-shaped units, giving access to ultra-large rings. ${ }^{27}$

As illustrated in Scheme 2, the composition of the catenanes is easily varied through alteration of the starting material and post-synthetic modification.

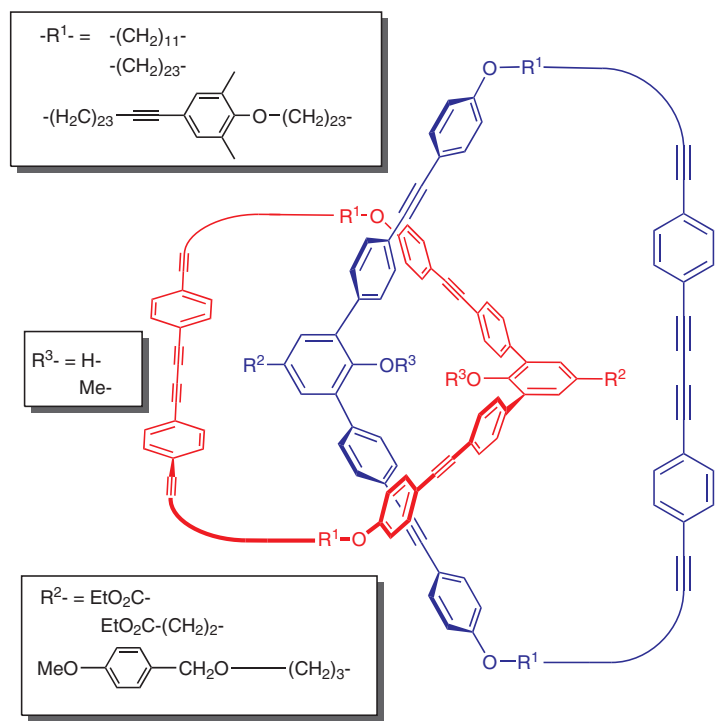

Scheme 2 Catenanes of varying ring size and substitution patterns synthesized by means of Godt's carbonate templating method ${ }^{24}$
In this way, catenanes with 67-, 87-, and 147-membered rings featuring different substitution patterns on the phenol were synthesized. This enabled, for example, the installation of carboxylic acid and alcohol moieties in the $\mathrm{R}^{2}$ position, which are useful motifs for polymerization. The synthesis of catenanes of varying ring sizes revealed that the ratio of unthreaded to interlocked products (e.g., 4/5) increased with larger ring sizes. To explain this trend, the authors hypothesize that the aliphatic part of the ring precursor in $\mathbf{3}$ is flexible enough to fold out of the macrocycle. This would leave the carbonate template outside of both rings leading to dethreading. Highlighting the scope of their method, the authors succeeded in synthesizing an unsymmetrical catenane comprised of two different rings. ${ }^{24}$ In this way, a catenane with rings carrying either an alcohol or carboxylic acid moiety was synthesized, producing a useful monomer for mechanically interlocked polymers.

\subsection{All-Benzene Catenanes on a Silicon Template}

Only very few papers describe the synthesis of catenanes solely consisting of hydrogen and carbon: Schill synthesized a cycloalkane catenane in $1983,{ }^{28}$ and it took 36 years before Itami and co-workers repeated this laudable accomplishment by preparing an all para-connected benzene catenane (Scheme 3).29,30 The lack of handles for preorganization in such hydrocarbons calls for extraordinary ingenuity from the synthetic chemist. Non-covalent strategies to all-hydrocarbon MiMs are virtually unthinkable due to the absence of heteroatoms, and Itami instead opted for a tetrahedral silicon template to interlock two cycloparaphenylene units (CPPs). CPPs can be regarded as slices of an armchair carbon nanotube and were first prepared by Jasti and Bertozzi in 2008. ${ }^{31}$ Exhibiting exotic properties due to their symmetry and extended $\pi$-conjugation, CPPs have become a hot topic in the field of nanocarbons and their synthesis has advanced accordingly.

Overcoming strain energy is the main hurdle in CPP synthesis and a popular solution is to include dialkoxycyclohexadiene units to bend the ring precursor, as seen in compounds $\mathbf{7}$ and $\mathbf{9}$. Dilithiation of $\mathbf{7}$ and $\mathbf{9}$ followed by a reaction with a complex of trichlorosilane and TMEDA ( $N, N, N^{\prime}, N^{\prime}$-tetramethylethylenediamine) successfully formed spirosilanes $\mathbf{8}, \mathbf{1 0},{ }^{29}$ and a [9]CPP/[9]CPP catenane precursor (not shown). ${ }^{30}$ Ring closing was achieved through $\mathrm{Ni}(0)$-mediated aryl-aryl coupling, after which desilylation gave catenanes 11, 12, and 13. Reductive aromatization of the dialkoxycyclohexadiene moieties then yielded the corresponding catenanes 14,15 , and 16 as well as non-interlocked CPP side products. [9]CPP/[9]CPP catenane $\mathbf{1 4}$ and [9]СPP/[12]CPP catenane $\mathbf{1 5}$ were obtained in significantly lower yield as compared to [12]CPP/[12]CPP catenane $\mathbf{1 6}$. DFT calculations showed that this discrepancy originates from the higher strain energy within the [9]CPP pseudocatenanes upon ring closure. ${ }^{30}$ 

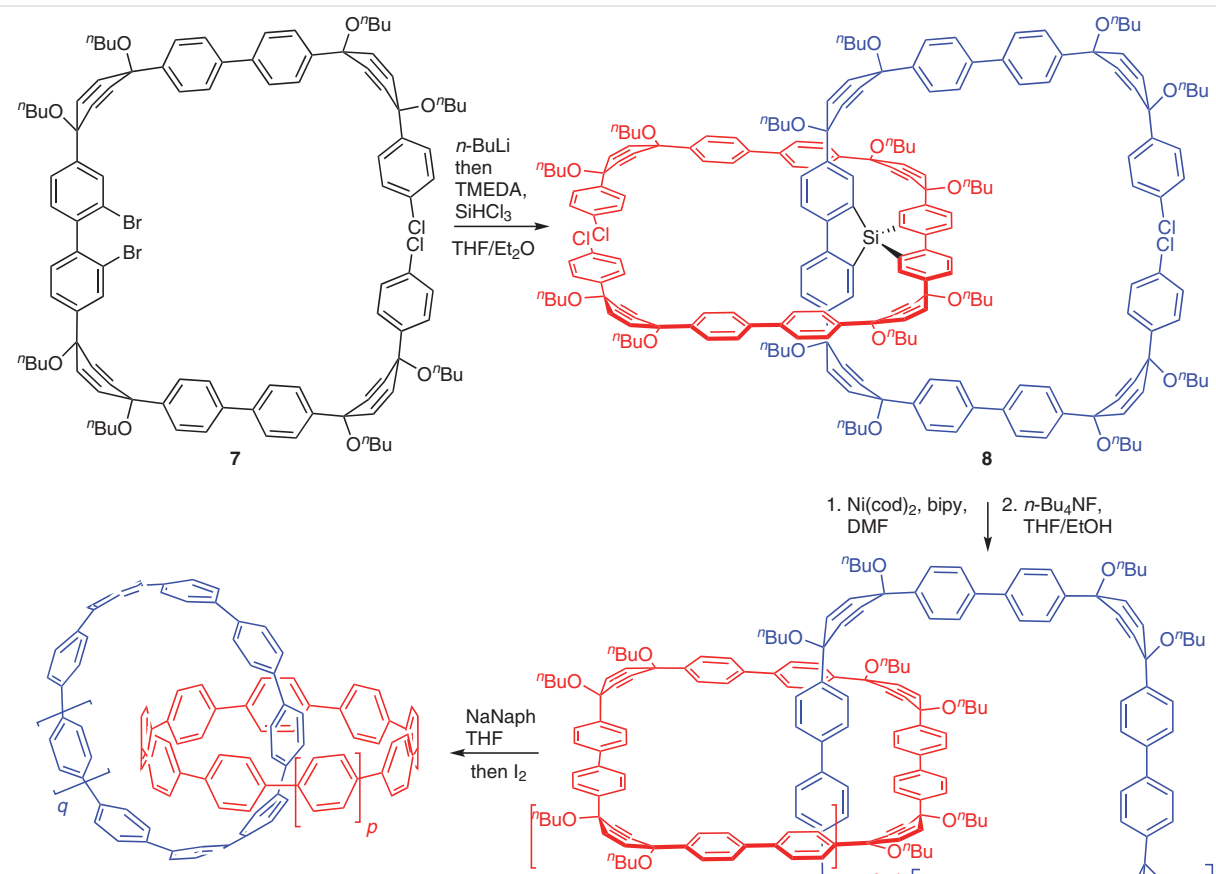

$$
\begin{aligned}
& 14(p=1, q=1) 0.8 \% \text { from } 9 \\
& +[9] \text { CPP } 16 \% \\
& 15(p=4, q=1) 0.6 \% \text { from } 9 \\
& +[9] \text { CPP } 13 \%[12] \text { CPP } 14 \% \\
& 16(p=4, q=4) 9.1 \% \text { from } 7 \\
& +[12] \text { CPP } 14 \%
\end{aligned}
$$
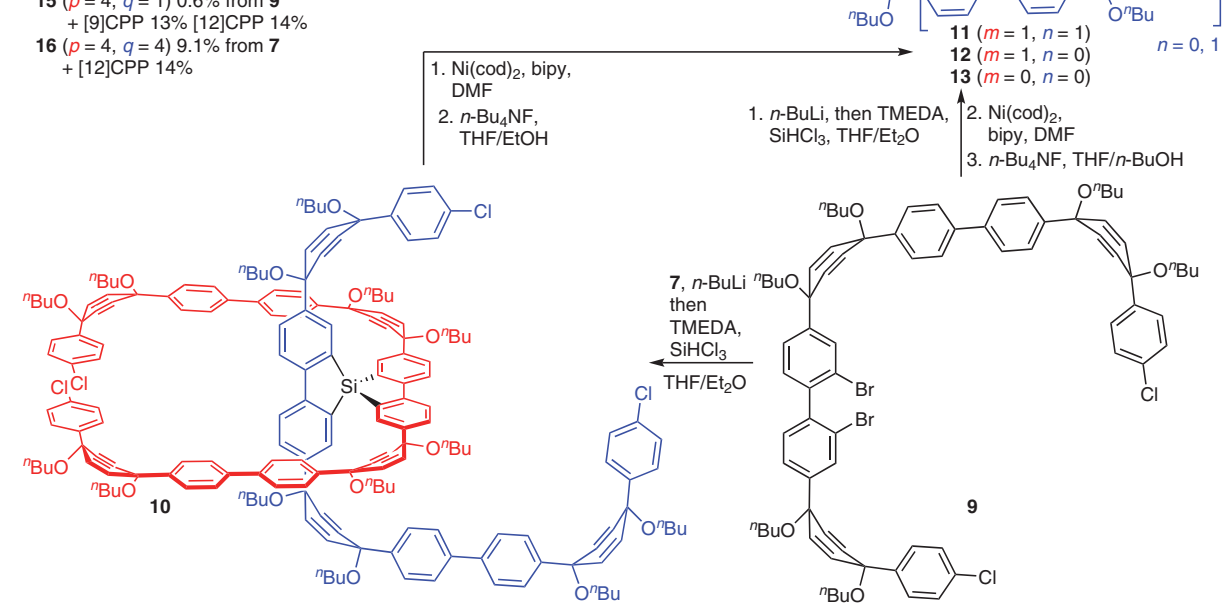

Scheme 3 Itami's synthesis of all-benzene catenanes 14,15 , and $16^{29,30}$

Remarkably, ${ }^{1} \mathrm{H}$ and ${ }^{13} \mathrm{C}$ NMR spectra of homocatenanes 14 and 16 contained only one resonance due to the rapid pirouetting of the interlocked rings. Calculations on homocatenane 14 showed that its LUMO and LUMO+1 were delocalized over both rings, while the HOMO and HOMO- 1 covered a single ring. Upon excitation of heterocatenane $\mathbf{1 5}$, energy transfer from the [12]CPP to the [9]CPP through the mechanical bond caused all emitted light to originate from the [9]CPP. While a solution containing non-interlocked [9]CPP and [12]CPP showed fluorescence peaks of both, fluorescence of the [12]CPP macrocycle in heterocatenane $\mathbf{1 5}$ was completely quenched. ${ }^{29}$ The authors hence demon- strated that through catenation the CPPs molecular orbitals could be coupled with completely preserved symmetry due to the unrestricted rapid pirouetting motion. A feat that seems impossible to achieve in another way.

In addition to catenanes, the silicon template was used to prepare a trefoil knot (Scheme 4 ). ${ }^{29}$ The trefoil knot is the simplest nontrivial knot, meaning that it cannot be untied without cutting one of it strands. Dilithiation and spirosilylation reactions were performed on dibromo compound $\mathbf{1 7}$ to give pseudocatenane 18. Homocoupling then resulted in dimer 19, which was converted into all-benzene trefoil knot $\mathbf{2 0}$ through the same desilylation and reductive aro- 
matization procedure. Knot $\mathbf{2 0}$ is chiral, and the left-handed trefoil was successfully resolved from its enantiomer using chiral HPLC. Even at $-95{ }^{\circ} \mathrm{C}$, NMR spectra of $\mathbf{2 0}$ showed just one signal, indicating rapid dynamic motion of the molecule. Simulations revealed that it is fast vortex-like motion of the knot that renders all 96 hydrogen atoms equivalent on the NMR timescale.

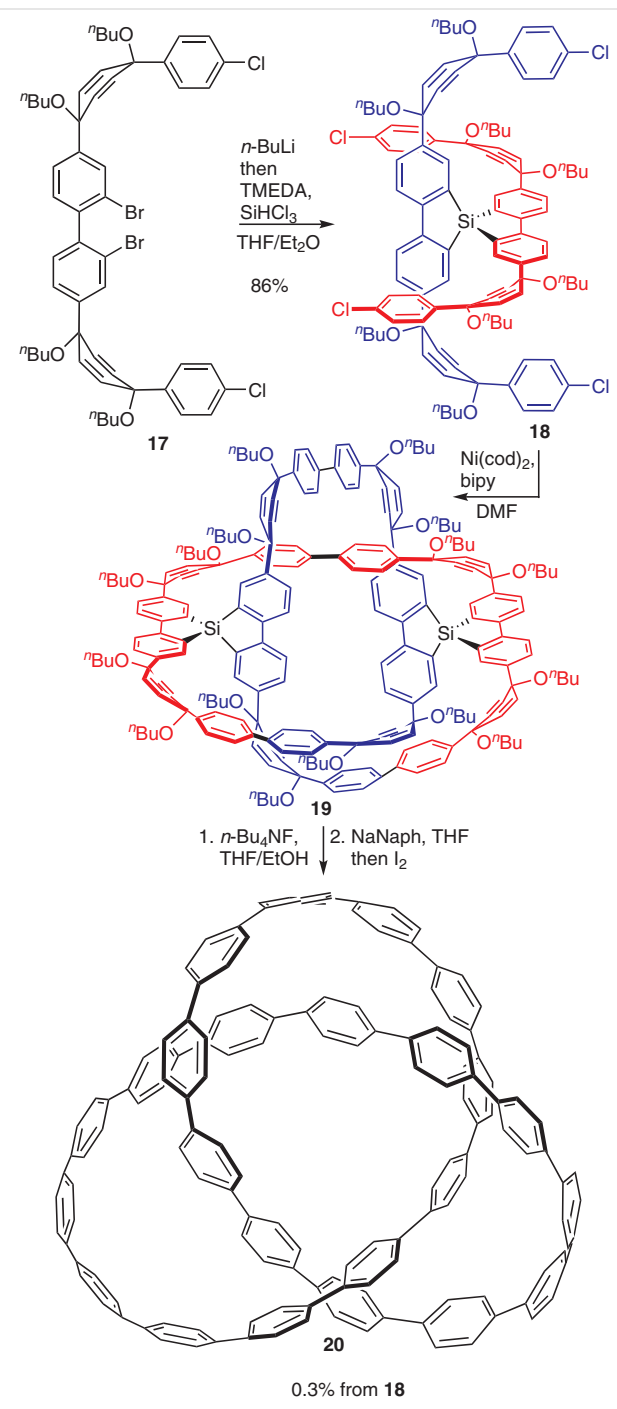

Scheme 4 Synthesis of trefoil knot $\mathbf{2 0}$ through Itami's silicon templating strategy ${ }^{29}$

\subsection{Backfolding from Quaternary Carbon}

Considering its ubiquity in organic chemistry, the choice for $\mathrm{sp}^{3}$-hybridized carbon as a tetrahedral template must come to no surprise. While orthogonality is aptly enforced by hybridization of the central quaternary carbon, the issue of interlocking the rings remains to be addressed. Using rigid ring precursors offers a solution, as demonstrat- ed in the works of Godt and Itami, but also flexible alkyl chains can be interlocked. Our group developed a templated backfolding strategy (schematically shown in Scheme 5), in which temporary linkages to an auxiliary enforce backfolding of the ring precursors, whereas direct cyclization results in a regular spiro compound. ${ }^{32}$ The auxiliary acts as a marriage broker with absolute authority over the wedding location: the bonds are sealed below the blue ring precursors, which are left no choice but to cyclize around the red ring.

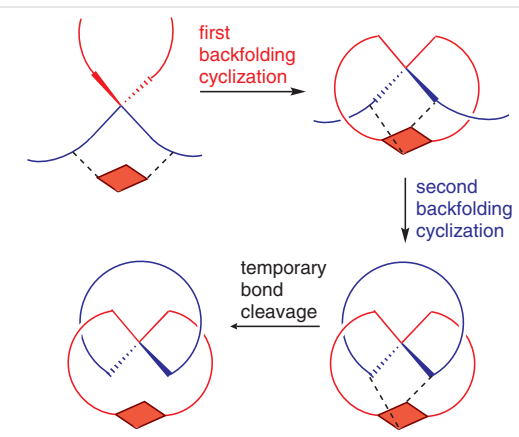

Scheme 5 Schematic representation of the templated backfolding method $^{32}$

The first proof of principle was provided in 2017 in the synthesis of what were deemed quasi[1]catenanes and quasi[1] rotaxanes (Scheme 6). ${ }^{32}$ The center of the inverted spiro compound consisted of an uncleavable $9 \mathrm{H}$-fluorene moiety, giving rise to the prefix 'quasi'. Starting from compound 21, the temporary linkages (in black) are coupled to diester 22 through transesterification. The resulting diyne $\mathbf{2 3}$ is all set for a double Cu-catalyzed azide-alkyne cycloaddition (CuAAC) to give 24, in which the red ring is folded around the blue ring precursors. Ring-closing metathesis followed by transesterification and protolytic cleavage of the temporary linkages then inevitably led to quasi[1]catenane 25. Alternatively, cross metathesis with stopper 26 and subsequent cleavage of the temporary linkages yielded quasi[1] rotaxane 27 , which proved resistant to unwinding even upon prolonged heating. The regular spiro diastereomer of $\mathbf{2 5}$ and the unwound isomer of $\mathbf{2 7}$ (not shown) were synthesized by altering the order of reactions. Performing cleavage of the temporary linkages via transesterification before ring-closing metathesis exclusively yielded the regular spiro conformation, whose formation is thus thermodynamically preferred but blocked by the temporary linkages. The NMR spectra of the unwound isomers clearly differed from 25 and 27, proving that the backfolding strategy had been successful.

Whereas a rigid fluorene moiety was used to ensure orthogonality in the synthesis of $\mathbf{2 5}$ and 27, we later showed that the backfolding strategy is compatible with a 'plain' central carbon atom linking four flexible alkyl chains (Scheme 7). ${ }^{33}$ The temporary linkages in $\mathbf{2 8}$ again place the red ring precursors above and below the central carbon at- 

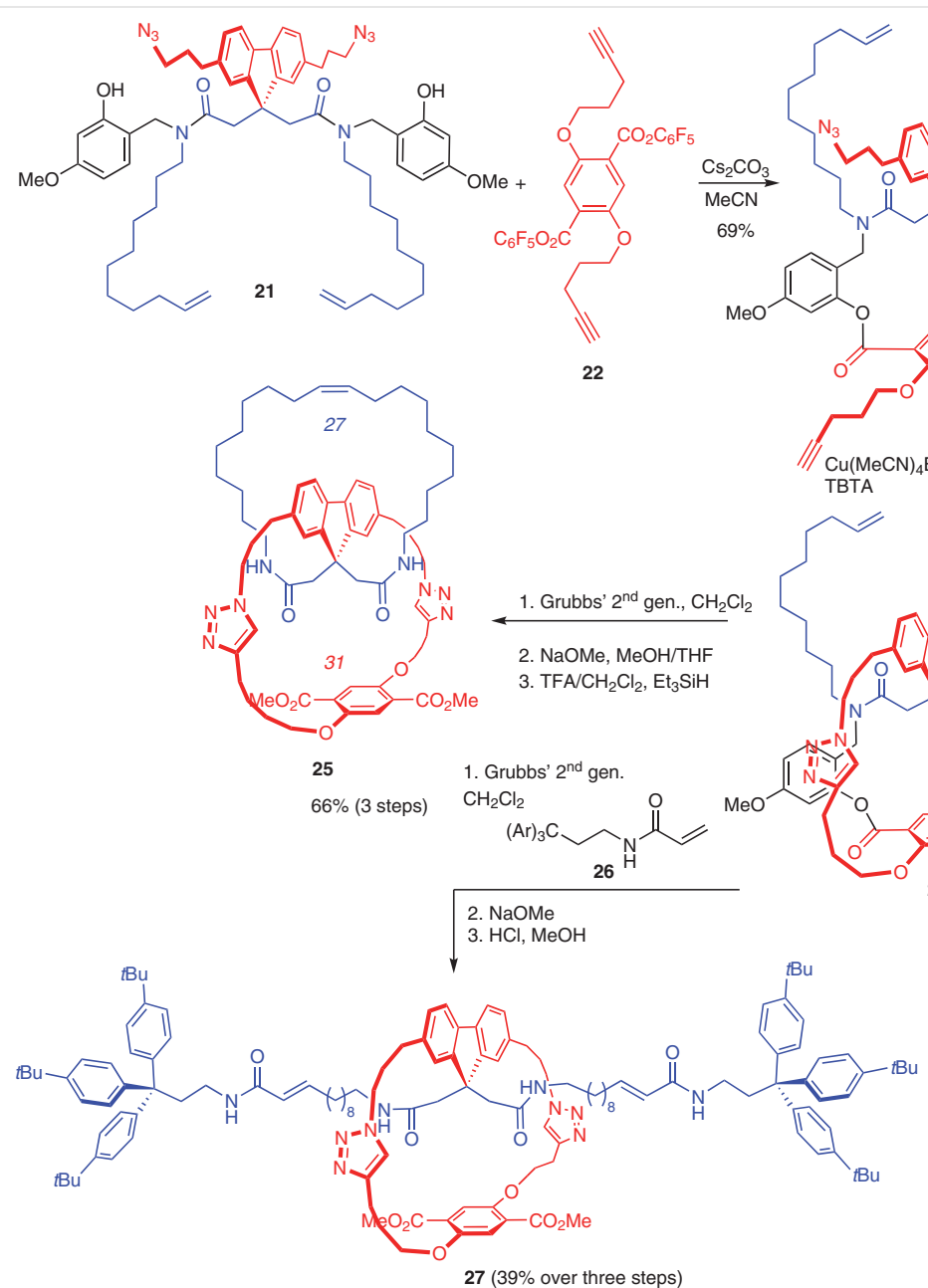

Scheme 6 Synthesis of quasi[1]catenane 25 and quasi[1]rotaxane 27 by means of a templated backfolding strategy ${ }^{32}$

om. This conformation guarantees the occurrence of backfolding cyclization to give diene 29. Subsequent ring-closing metathesis yielded bicycle $\mathbf{3 0}$ in modest yield, after which cleavage of the temporary linkages and catalytic hydrogenation resulted in quasi[1] catenane $\mathbf{3 1}$. The diastereomer of 31 with regular spiro geometry (not shown) was again synthesized through early temporary linkage cleavage. Calculations showed only a very small energy difference between 31 and its diastereomer, from which can be concluded that additional van der Waals interaction and ring strain are absent within the $27+27-$ membered inverted spiro compound.

Looking for a scissile central template, we drew inspiration from Schill's synthesis of a [2]catenane using a cyclic ketal template. ${ }^{34}$ As shown in Scheme 8, we similarly employed a cyclic ketal derived from L-(+)-tartaric acid with the intent of preparing a [2]catenane using acidic hydroly- sis as a final step. Our first attempt with amide moieties in the red ring (compounds 32a-34a) was unsuccessful, ${ }^{35}$ since precatenane $\mathbf{3 4 a}$ could not be hydrolyzed due to the stabilizing effect of the amide groups on the nearby ketal. A successful route was found from $\mathbf{3 2 b}$ by inclusion of ethylidene instead of the amide groups. ${ }^{36}$ Ring-closing metathesis yielded 33b in moderate yield, after which catalytic hydrogenation and cleavage of temporary linkages resulted in precatenane $\mathbf{3 4 b}$.

Under strongly acidic conditions, the rings could be liberated to give catenane $\mathbf{3 5 b}$ as the first example of a successful covalent template backfolding approach towards MIMs. Interestingly, hydrolysis of its regular spiro diastereomer (not shown) was easily achieved, demonstrating the influence of the catenane effect on the stability of $\mathbf{3 4 a}$ and 34b. 

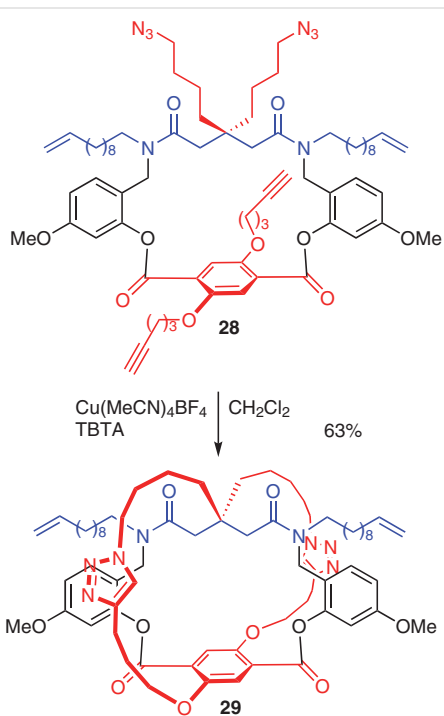

Grubbs' $2^{\text {nd }}$ gen., $\mid \mathrm{CH}_{2} \mathrm{Cl}_{2} \quad 47 \%$

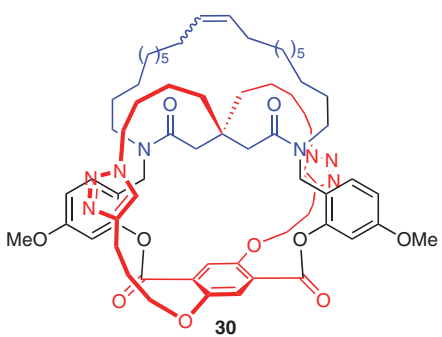

1) $\mathrm{K}_{2} \mathrm{CO}_{3}, \mathrm{MeOH}$ 3) $\mathrm{H}_{2}, \mathrm{Pd} / \mathrm{C}$

2) $\mathrm{HCl}, \mathrm{MeOH} \downarrow \mathrm{THF} / \mathrm{EtOAc} 73 \%$ (over three steps)

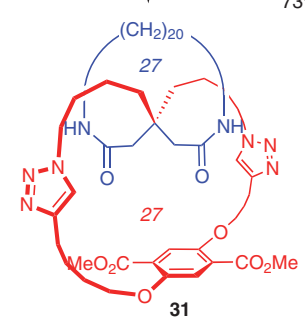

Scheme 7 Preparation of quasi[1] catenane $\mathbf{3 1}$ with a central carbon atom linking four flexible alkyl chains ${ }^{33}$

\section{Planar Templates}

Aromatic systems generally exhibit predictable reactivity and a high degree of rigidity, rendering them particularly useful covalent templates. Implementing these templates usually results in distorted square planar geometries, which leaves the precursors on nearly orthogonal axes. This leads to interlocked species if spatial control can be established through rigidity of the components, backfolding, or by restricting the approach of an incoming reactant.

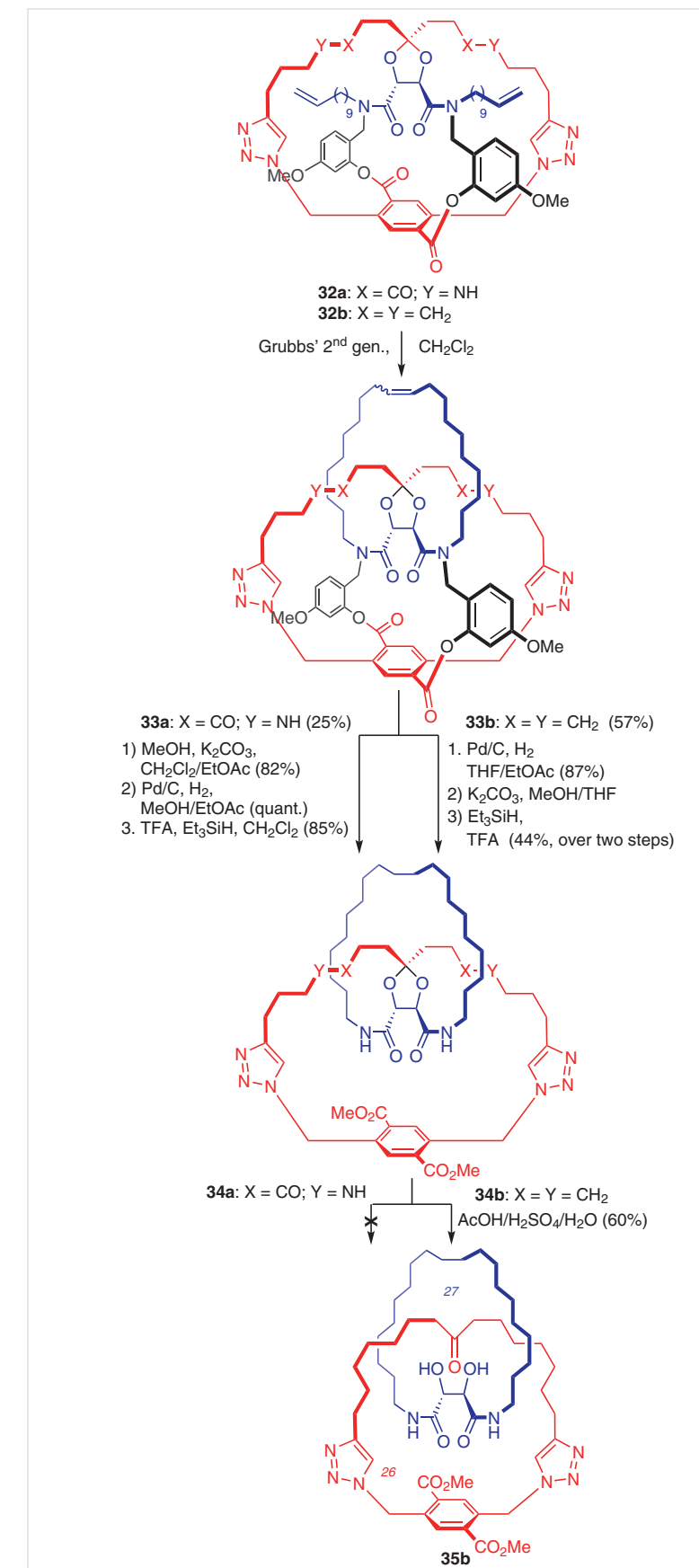

Scheme 8 A successful and unsuccessful templated backfolding approach towards [2]catenane $\mathbf{3 5}$ using a cyclic ketal template ${ }^{35,36}$

\subsection{Rotaxanes Constructed in a Ring}

The Hiratani group reported a rather exceptional synthesis of rotaxanes in 2002, in which preorganization was imparted by the ring instead of the axle (Scheme 9). ${ }^{37}$ Another distinguishing feature of the approach is the simultaneous capping and cleavage of the axle through aminolysis. 

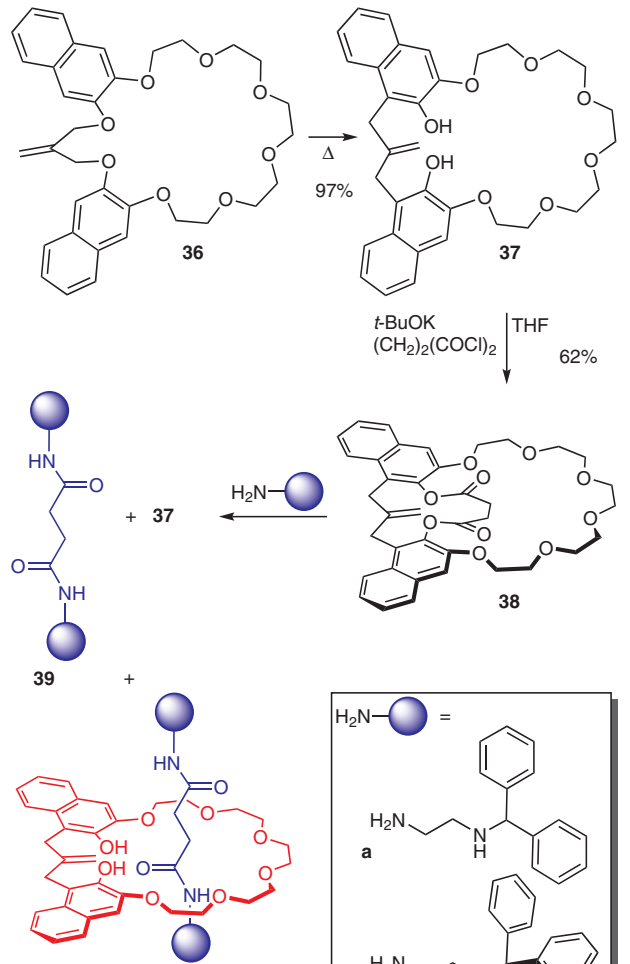

$40 \mathrm{a}(26 \%)+37(69 \%)$ $+39(74 \%)$ $40 \mathrm{~b}(42 \%)+37(44 \%)$ $40 \mathrm{~b}(42 \%)+37$
$+39(27 \%)$ $40 \mathrm{c}(56 \%)+37(28 \%)$ $+56 \%)+37(28 \%)$
$+39(34 \%)$

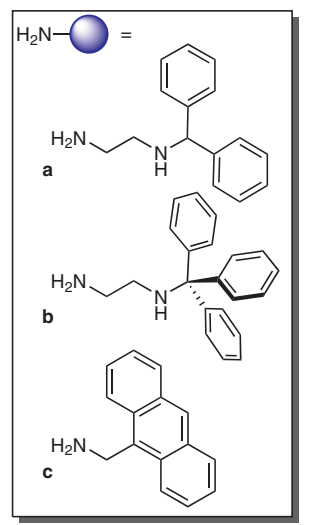

Scheme 9 Hiratani's synthesis of [2] rotaxanes $40 a-c$ through simultaneous capping and cleavage of axle $\mathrm{e}^{37,38}$

Hiratani had earlier found an efficient route towards crownophane $\mathbf{3 7}$ by means of a tandem Claisen rearrangement of polyether 3 36. $^{38}$ The resulting phenolic hydroxy groups are favorably positioned inside the crownophane, enabling binding of substrates within the cavity of ring. The planar diester template is formed through a reaction with succinyl chloride to give bicycle $\mathbf{3 8}$. The substrate scope of the diesterification, and consequently the axle, is quite limited as the use of extended diacyl chlorides led to oligomerization of 37, while smaller substrates such as malonyl chloride gave no reaction. Conveniently, simple addition of an amine stopper (a-c) to bicycle $\mathbf{3 8}$ simultaneously attached stoppers to the axle and liberated the ring to yield rotaxanes $\mathbf{4 0 a - c}$, as well as non-interlocked ring $\mathbf{3 7}$ and axle $\mathbf{3 9}$ as side products. The preference for the threaded product originates from the steric effects exerted after attachment of the first stopper. The second amine is then more likely to approach from the other side of the macrocycle to evade the steric bulk. This is supported by the yields of the reactions of $\mathbf{3 8}$ with the stoppers a-c, since the least bulky stopper a gives more side products because in that case the second attack more easily occurs from the same side.

Cleverly exploiting the formation of the monoester isomer, Hiratani was later able to synthesize and resolve a chiral rotaxane (Scheme 10). ${ }^{39}$ Incorporation of a catechol unit in crownophane 41 resulted in a prochiral ring, which formed a chiral product when reacted with two different stoppers. An esterification reaction with acyl chloride $\mathbf{4 2}$ gave monoester $\mathbf{4 3}$ as well as its isomer. Without prior separation, the mixture was subjected to aminolysis with the anthrylmethanamine stopper to yield rotaxane $\mathbf{4 4}$. Chiral HPLC resulted in clear enantiomeric separation of $\mathbf{4 4}$, although separation of other chiral rotaxanes with more extended axles (not shown) proved unsuccessful.

The same group conceived a synthesis of a [1]rotaxane based on the inclusion of an amine in crownophane $\mathbf{4 5}$ (Scheme 11), ${ }^{40}$ from which branching through the macrocycle occurred. First, dodecanedioyl dichloride was added to yield bicyclic compound $\mathbf{4 6}$ in poor yield, presumably due to oligomerization-type side reactions. Although the approach on the opposite side of the alkyl chain in $\mathbf{4 6}$ is less hindered, aminolysis with stopper $\mathbf{4 7}$ gave a separable mixture of [1] rotaxane $\mathbf{4 8}$ and its unwound isomer 49. In contrast to unwound $\mathbf{4 9}$, [1] rotaxane $\mathbf{4 8}$ was shown to capture

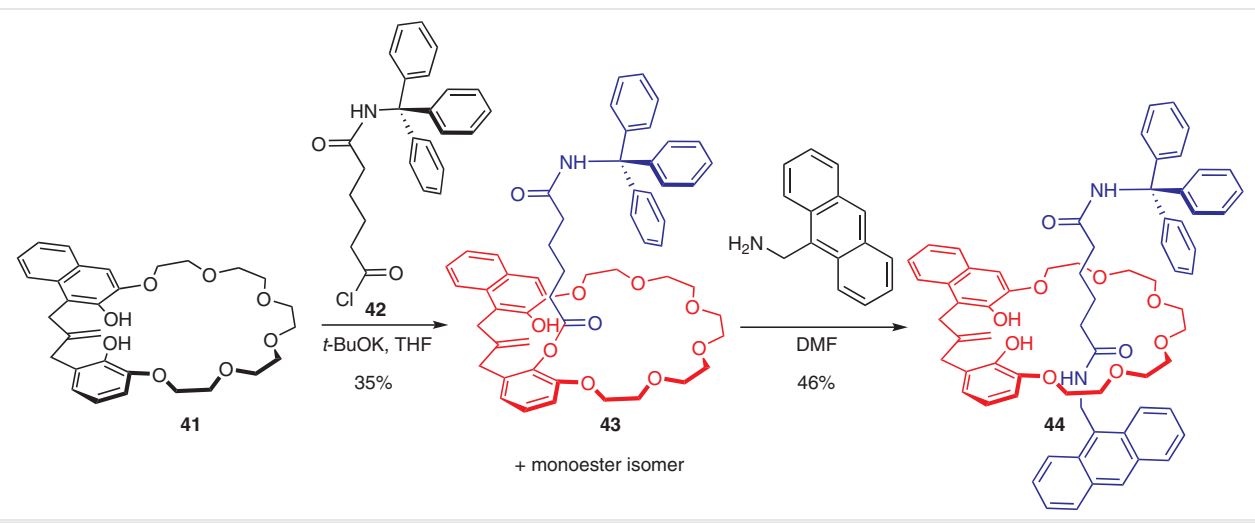

Scheme $\mathbf{1 0}$ Synthesis and resolution of chiral [2]rotaxane $\mathbf{4 4}$ by Hiratani's group ${ }^{39}$ 

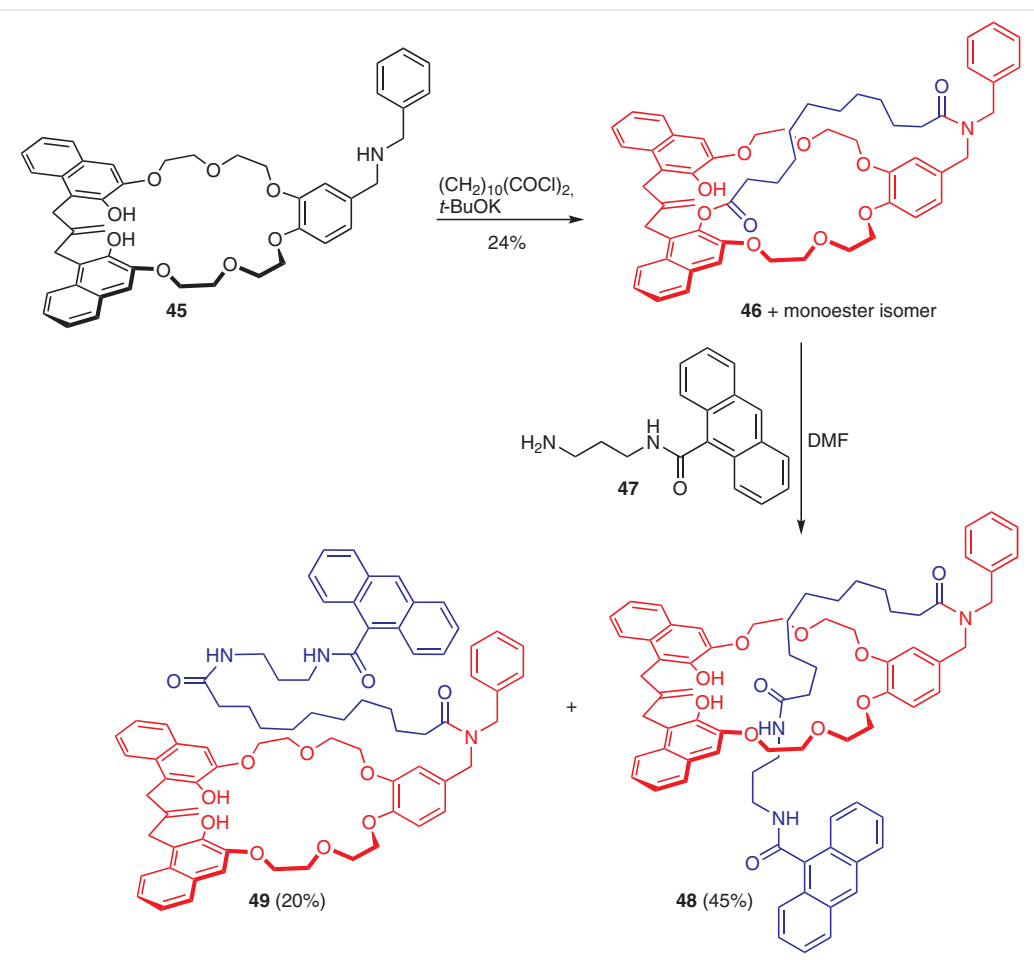

Scheme 11 Hiratani's synthesis of [1]rotaxane $\mathbf{4 8}$ through aminolysis ${ }^{40}$

a lithium ion in its cavity marked by the polyether and amide groups. Energy transfer of the naphthalene groups in the ring to the anthracene stopper is significantly increased upon $\mathrm{Li}^{+}$capture as was reflected in the fluorescence spectra of 48. The conformational change upon binding of the cation brings the donor-acceptor pair closer together and the host-guest interaction consequently affects energy transfer within the rotaxane. Remarkably, [1]rotaxane $\mathbf{4 8}$ showed no affinity for other alkali metal ions, making it potentially useful as a selective lithium ion-sensing agent.

Returning to crownophane 37, Hiratani expanded the method to [3]rotaxanes through diesterification of linker $\mathbf{5 0}$ to form pseudo[3]rotaxane $\mathbf{5 1}$ (Scheme 12). ${ }^{41}$ The rigidity and length of $\mathbf{5 0}$ favors dimerization over intramolecular diesterification. Subsequent aminolysis with the anthrylmethanamine stopper then yields a mixture of [3]rotaxane 52, [2]rotaxane 53, and non-interlocked ring and axle side products (yields not reported). Interestingly, [2]rotaxane 53 is the major product, but the ratio of $\mathbf{5 2}$ to $\mathbf{5 3}$ is higher than would be statistically expected. [3]Rotaxane 52 can be formed in just one way through double outside attack, while there are two combinations of inside and outside attack which yield [2]rotaxane 53. The higher ratio indicates the existence of a driving force towards formation of $\mathbf{5 2}$. Also [3] rotaxane $\mathbf{5 2}$ was shown to be capable of capturing cations. Similar to [1] rotaxane 48 , two $\mathrm{Li}^{+}$ions can be bound in the cavities of the individual rings of [3]rotaxane 52. A cesium ion, by contrast, was captured between the two rings of $\mathbf{5 2}$ to form a sandwich structure. ${ }^{41}$

\subsection{Hydrindacene as a Dynamic Covalent Template}

The synthesis of a [2]rotaxane with a unique dynamic covalent imine bond was achieved by Kawai in 2006.42 The authors employed a hydrindacene (1,2,3,5,6,7-hexahydro$s$-indacene) template, which forms a versatile scaffold as it allows positioning of substituents on three orthogonal axes. ${ }^{43}$ Meanwhile, it is sufficiently flexible to give a conformational response upon complexation, making it a suitable supramolecular building block in, for example, receptors. ${ }^{44}$ In rotaxane synthesis, preorganization of ring and axle on two orthogonal axes is sufficient as was achieved with dialdehyde 54 (Scheme 13). The bulkier aromatic substituents occupy the pseudo-axial positions, leaving the aldehyde groups on opposite sides of the hydrindacene core. In presence of molecular sieves to shift the equilibrium towards imine formation, the rigid diacetylene macrocycle $\mathbf{5 5}$ threads $\mathbf{5 4}$ in excellent yield. The success of this reaction can be explained by the rigidity of macrocycle and template, leaving the unthreaded conformer highly strained. Catalytic hydrogenation then yielded pseudorotaxane 56, whose conformation with the macrocycle placed perpen- 


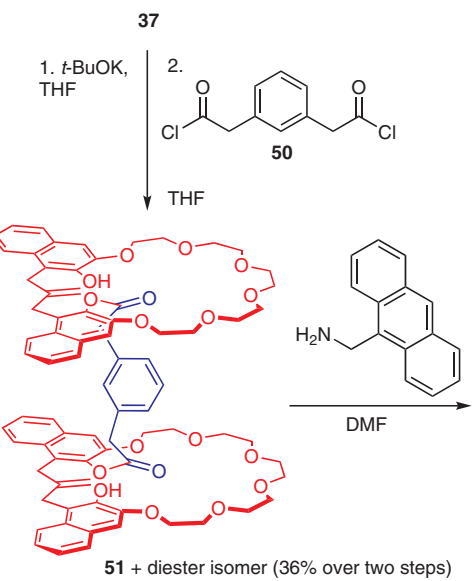

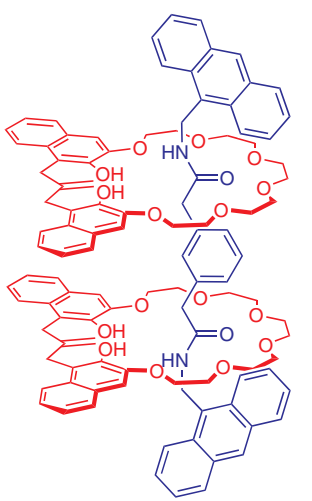

$52(20 \%)$

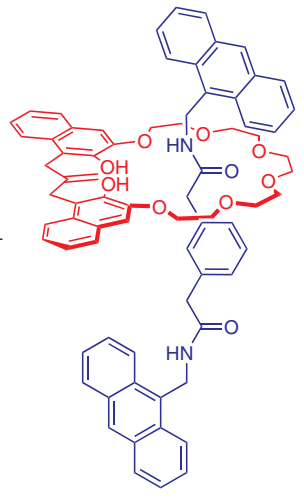

$53(32 \%)$

Scheme 12 Preparation of [3] rotaxane 52 and [2] rotaxane $\mathbf{5 3}$ which are capable of capturing cations ${ }^{41}$

dicular on the axle was validated via X-ray crystallography. Next, disilyl ether $\mathbf{5 6}$ was capped with stopper $\mathbf{5 7}$ in a desilylation-benzylation reaction to give prerotaxane $\mathbf{5 8}$.
Although prerotaxane derivatives with trityl stoppers dethreaded upon acidic hydrolysis, the larger stoppers of $\mathbf{5 8}$ successfully trapped the ring, and an equilibrium was found between $\mathbf{5 8}$, monoimine 59, and [2] rotaxane $\mathbf{6 0}$ (Scheme

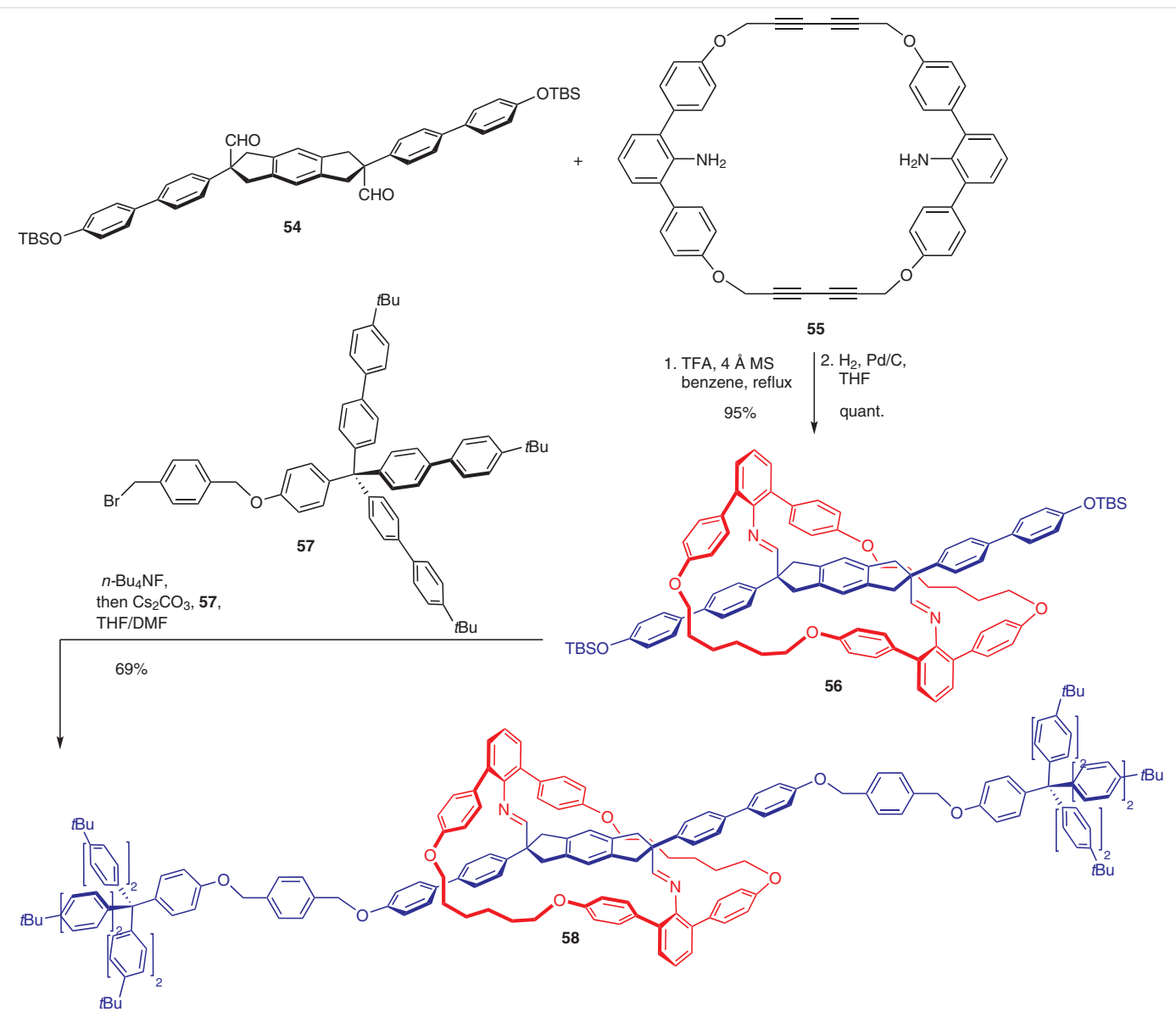

Scheme $\mathbf{1 3}$ Kawai's synthesis of prerotaxane $\mathbf{5 8}$ using a hydrindacene template ${ }^{42}$ 
14). ${ }^{42}$ The dynamic covalent bond between ring and axle showed a remarkable temperature dependence. Increasing temperature shifted the equilibrium towards bisimine $\mathbf{5 8}$, while cooling promoted formation of [2]rotaxane $\mathbf{6 0}$. This indicates that imine formation and release of water is en- tropically driven, whereas the reverse hydrolysis reaction is enthalpically driven. As a consequence, this system has the exceptional property that the mobility of the macrocycle is increased at lower temperatures. Translational and rotational movement normally increase upon heating, but in $\mathbf{6 0}$

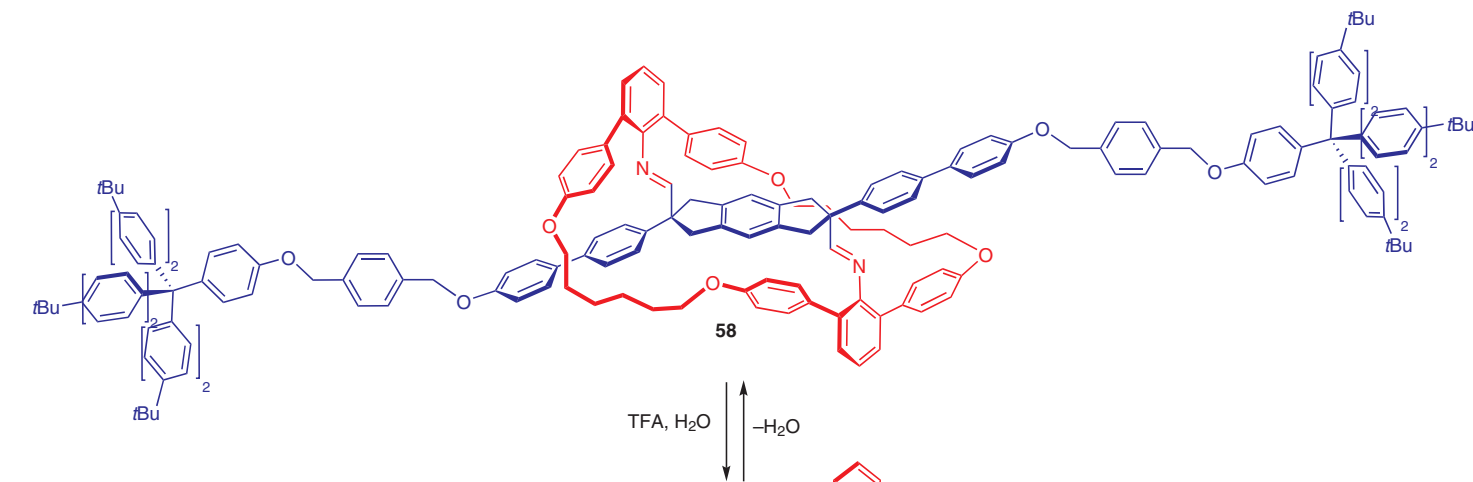

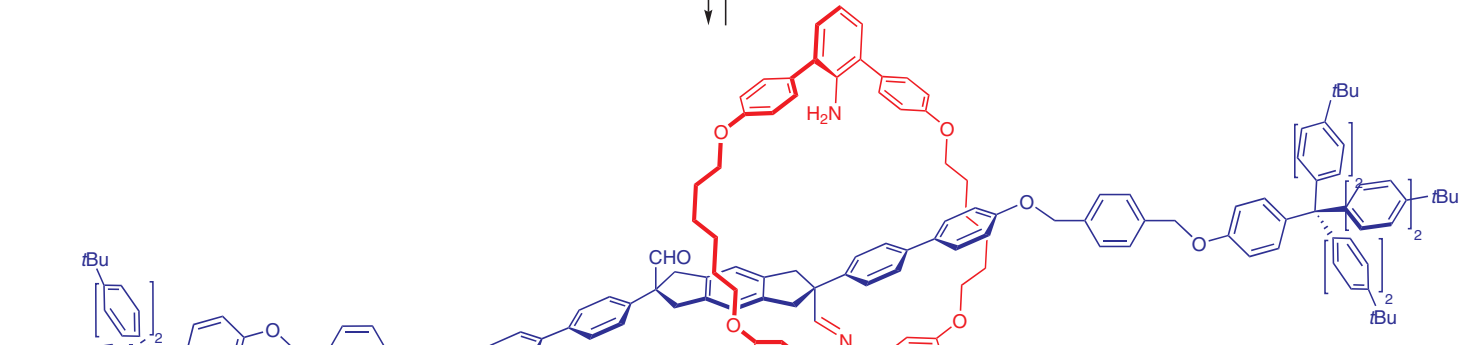

$$
\text { BBu- }
$$

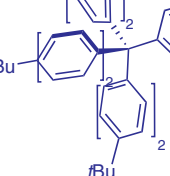<smiles>COc1ccc(COc2ccccc2)cc1</smiles><smiles>c1ccc2c(c1)CCCCCCCCCCCCCC2</smiles>

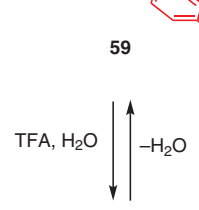

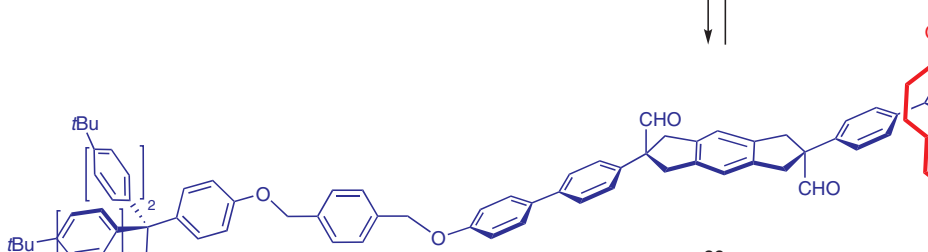<smiles>C1CCC2CCCC2C1</smiles>

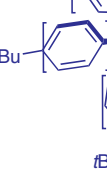<smiles>Brc1ccc(Br)cc1</smiles>

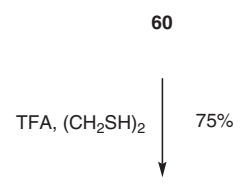<smiles>C=CCCCOc1ccc(-c2cccc(-c3ccc(OC)cc3)c2N)cc1</smiles>

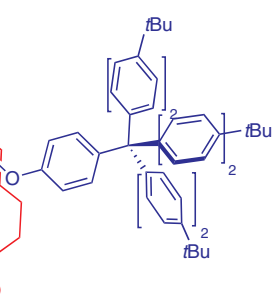

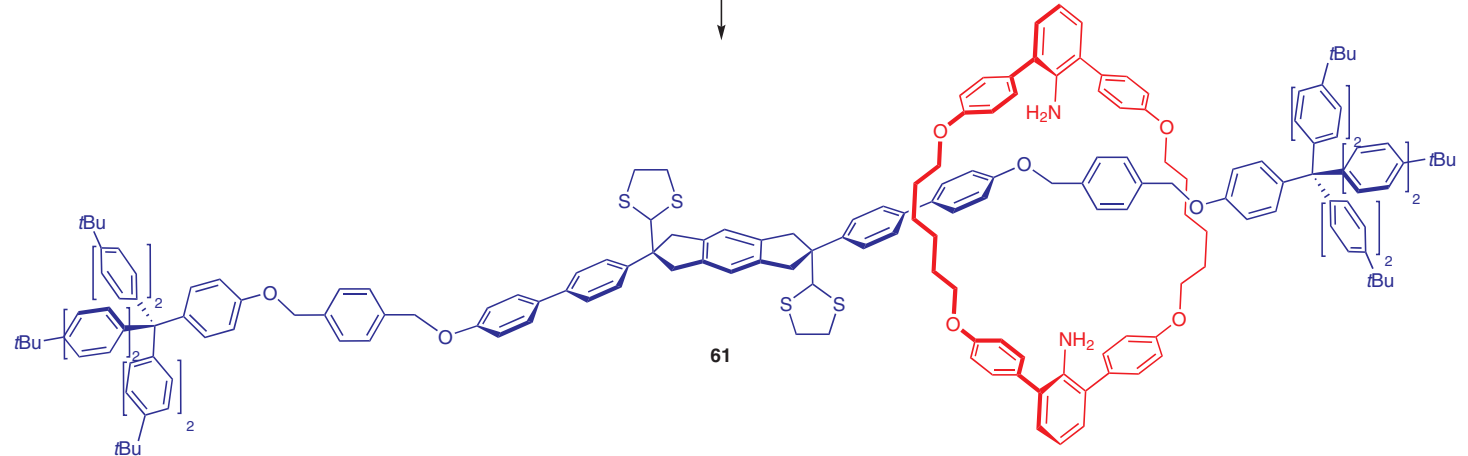

Scheme 14 The equilibria arising from the dynamic covalent bond in prerotaxane $\mathbf{5 8}$, which can be driven fully towards [2] rotaxane $\mathbf{6 1}$ by means of dithioacetalization ${ }^{42}$ 
the macrocycle is apprehended once the speed limit is exceeded. The equilibrium can be driven fully towards [2]rotaxane $\mathbf{6 1}$ by means of dithioacetalization. ${ }^{1} \mathrm{H}$ NMR analysis showed that the macrocycles of $\mathbf{6 0}$ and $\mathbf{6 1}$ reside on the xylylene ethers and rapidly shuttle between the two sides.

To design a prerotaxane which can be completely converted under hydrolytic conditions, Kawai introduced a triethylene glycol spacer in place of xylylene to include a hydrogen bonding station for the macrocycle (Scheme 15). ${ }^{45}$ Hydrogen bonding between macrocycle and spacer is both enthalpically favored and entropically disfavored, hence doubly amplifying the temperature dependence of the system. The authors were indeed able to exert remarkable control over the dynamic system by altering acidity and temperature or using dehydration conditions. The equilibrium could be fully shifted to either the [2]rotaxane or bisimine products at differing temperatures, depending on the set of conditions used. Interestingly, by including triethylene glycol spacers and increasing acidity, shuttling became slower than the NMR timescale due to the strong hydrogen bonding between the components.

The same group reported a comprehensive study of the influence of individual components on the properties of the imine-bridged system (Scheme 15). ${ }^{46}$ To probe electronic and steric effects on the system, the library was expanded with a bulkier hexahydropyrene core, a xylylene macrocycle with smaller cavity, a rigid hexadiyne macrocycle, and electron-donating or electron-withdrawing substituents in para position to the imine. It was found that efficiency of threading was independent of the bulkiness of the axle and instead increased with the rigidity of the macrocycle. Electron-donating substituents also had a positive effect on threading as they promoted imine formation. While the rigid macrocycle gave the best results during threading, it proved less suitable for hydrolysis and gave no conversion into the [2]rotaxane product, even in presence of hydrogen bonding stations. This was explained by the limited rotational freedom and less efficient hydrogen bonding of the rigid macrocycle. The xylylene macrocycle was more readily hydrolyzed, probably due to increased steric repulsion with the core, but a sizeable proportion of the monoimine remained. In the smaller ring, the distance between the amines is decreased, disfavoring hydrogen bonding and hence lowering the energetic reward of full hydrolysis. Whereas the original choice of macrocycle seems to remain correct, a bulkier axle did positively affect hydrolysis as increased repulsion favored liberation of the ring. ${ }^{46}$

\subsection{Templating on Tri- and Tetrasubstituted Ben- zenes}

Benzene derivatives are ideal covalent templates because of their rigidity, wide availability, and well-defined chemistry. Höger had earlier utilized these traits in covalently templated syntheses of macrocycles, ${ }^{47}$ and in 2007 prepared a prerotaxane wire with a benzene core (Scheme 16). ${ }^{48}$ With Höger's goal of synthesizing a polymeric multichromophoric system for light harvesting, a covalent template is most suited due to its enhanced stability as compared to supramolecular assemblies. Starting from tetrayne

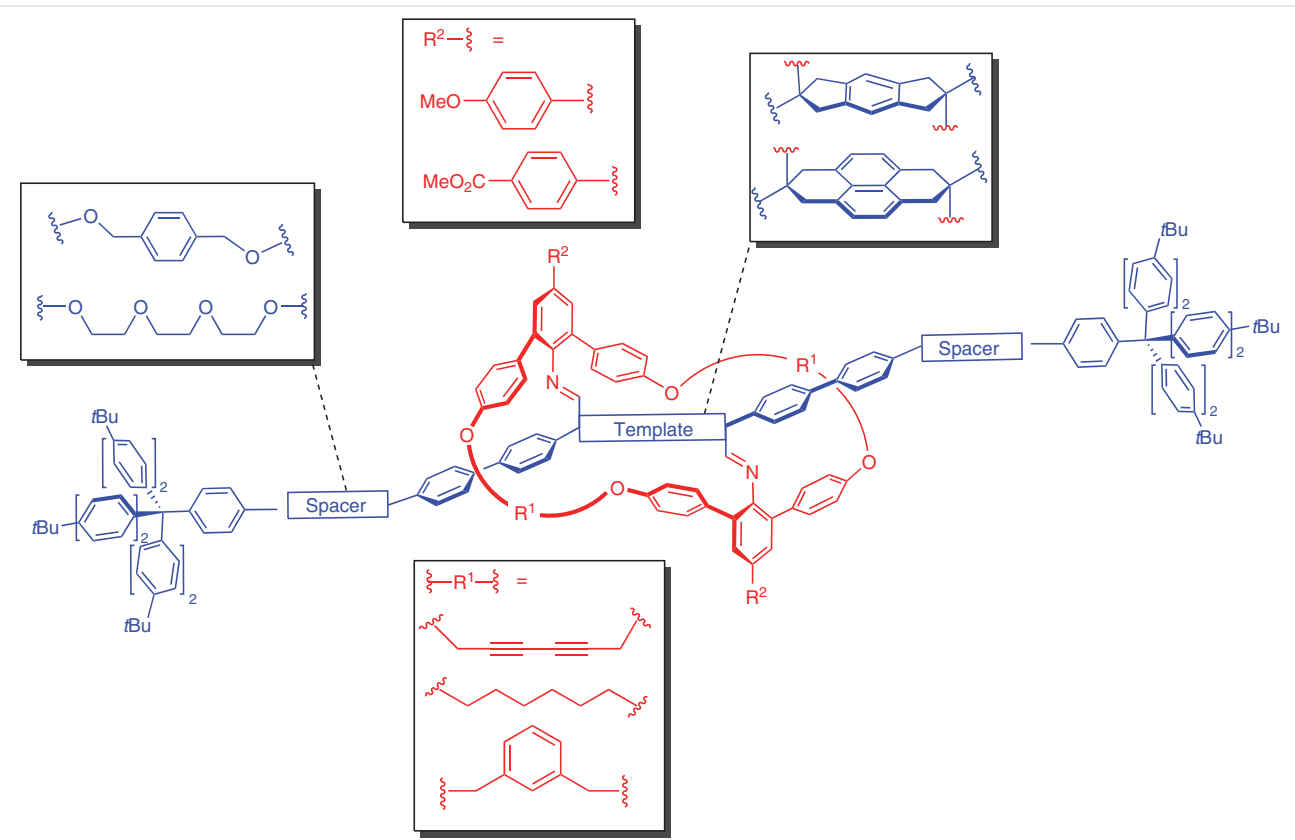

Scheme 15 [2]Rotaxanes featuring different, spacers, templates, and substitution patterns as synthesized by the Kawai group ${ }^{45,46}$ 
62, the two templated ring precursors were coupled through oxidative dimerization of alkynes under pseudohigh dilution conditions to give diiodo compound 63 in excellent yield. A Sonogashira coupling of $\mathbf{6 3}$ and protected linker $\mathbf{6 4}$ was followed by desilylation to give pseudorotaxane 65. Oxidative acetylene polymerization then afforded 66, a $\pi$-conjugated wire threaded through a tube of macrocycles. The authors did not provide proof for the interlocked conformation of the wire and macrocycles. The orthogonality is proposedly enforced by the stepwise coupling of $\mathbf{6 3}$ and 64, since the second linker would have a more favorable approach from the macrocycle's face opposite to the first linker. Despite its resemblance, polymer $\mathbf{6 6}$ is not readily converted into an interlocked compound because of the stable ether linkages between axle and thread. ${ }^{48}$

Morin and co-workers replaced these ether linkages for cleavable ester bonds, aiming to extend this method to rotaxanes (Scheme 17). ${ }^{49}$ Following Höger's templated macrocyclization approach, ${ }^{50}$ ring 67 was obtained with the same aryl iodides for orthogonal axle assembly. Since ring closure

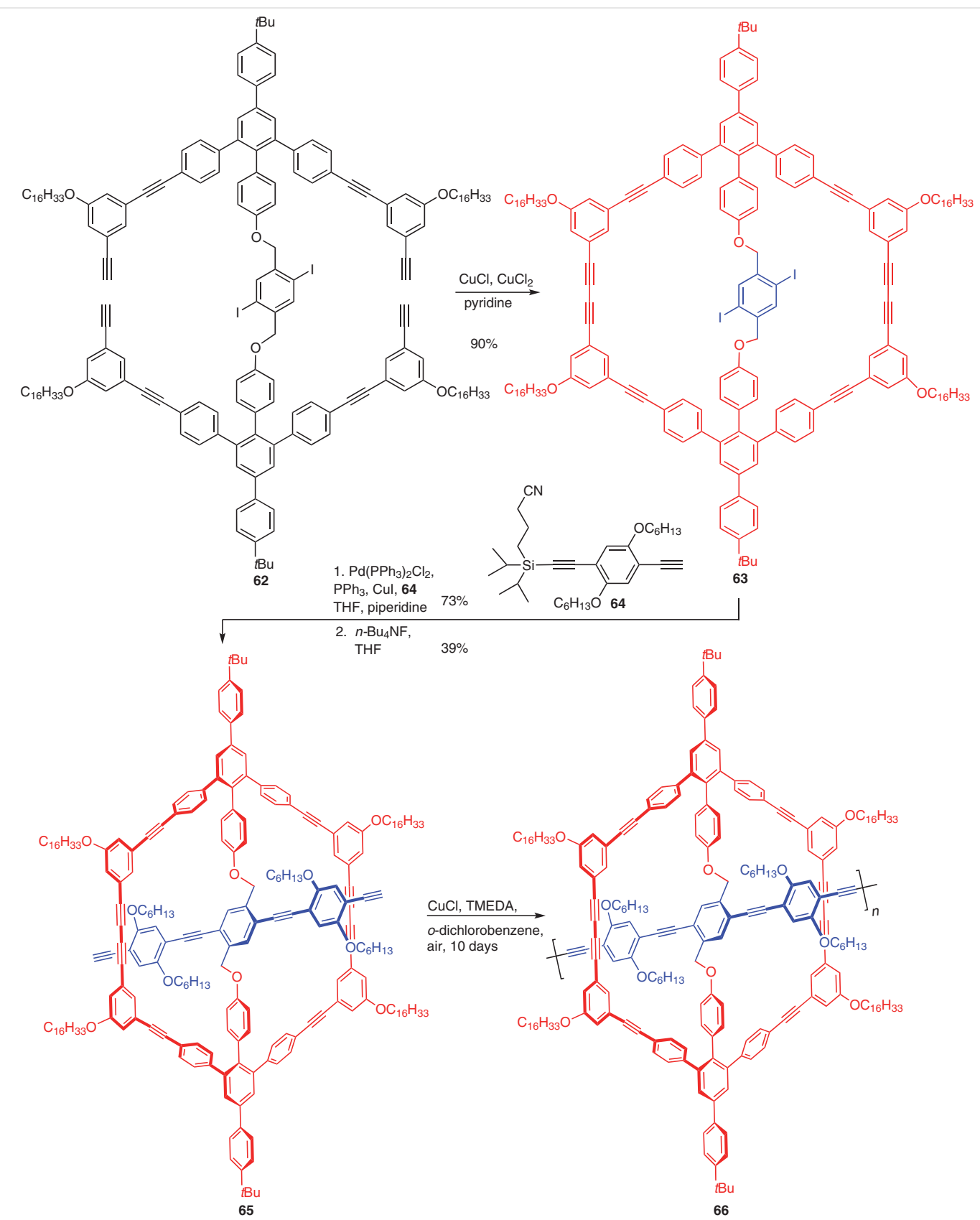

Scheme 16 Höger's synthesis of prerotaxane wire $\mathbf{6 6}$ with a benzene core ${ }^{48}$ 
attempts with ethyl ring spacers had failed due to steric repulsion in the cavity of the macrocycle, ring $\mathbf{6 7}$ was linked to the template with longer propyl groups. A Sonogashira coupling of macrocycle $\mathbf{6 7}$ and stopper 68 was intended to yield prerotaxane $\mathbf{6 9}$, but subsequent hydrolysis gave a mixture of non-interlocked axle and thread.

This is likely caused by the flexibility of the propyl spacers which facilitated formation of its unthreaded conformer. Even bulkier stoppers were employed in the synthesis, but to no avail. This proves that slippage is an unlikely explanation, leaving the flexible propyl chains as the culprit. The solution seems to include more rigid ring spacers to prevent dethreading, but this direction was unfortunately not pursued by the Morin group.

An improved approach with a rigid phenylene ring spacer was reported by Höger in 2016 (Scheme 18). ${ }^{51}$ Ring 70 was again prepared through oxidative dimerization of alkynes, but was this time templated by a core extended with two phenylene groups. Linkers 64a and 64b of varying size were coupled through a Sonogashira reaction and subsequently deprotected to give pseudorotaxanes 71a and 71b. The linkers now provided sufficient space to minimize steric repulsion upon attachment of macrocyclic stopper 72, which was readily coupled with yet another Sonogashira reaction. The ester linkages of the central macrocycle were selectively cleaved through aminolysis, leaving the benzylic ether bonds of the stoppers intact, to yield [2]rotaxanes $\mathbf{7 3 a}$ and $\mathbf{7 3 b}$ in surprisingly low yields. The presence of free axle and macrocycle in reaction mixtures of 73a and 73b indicated that dethreading had occurred, either because of formation of the unthreaded isomer or slippage of the macrocycle after aminolysis. Pure samples of [2]rotaxanes $\mathbf{7 3 a}$ and $\mathbf{7 3 b}$ were stored for a prolonged time at room temperature, after which MS analysis clearly confirmed the presence of free axle and ring. This leaves slippage of the macrocycle over the equally sized, shape-per-

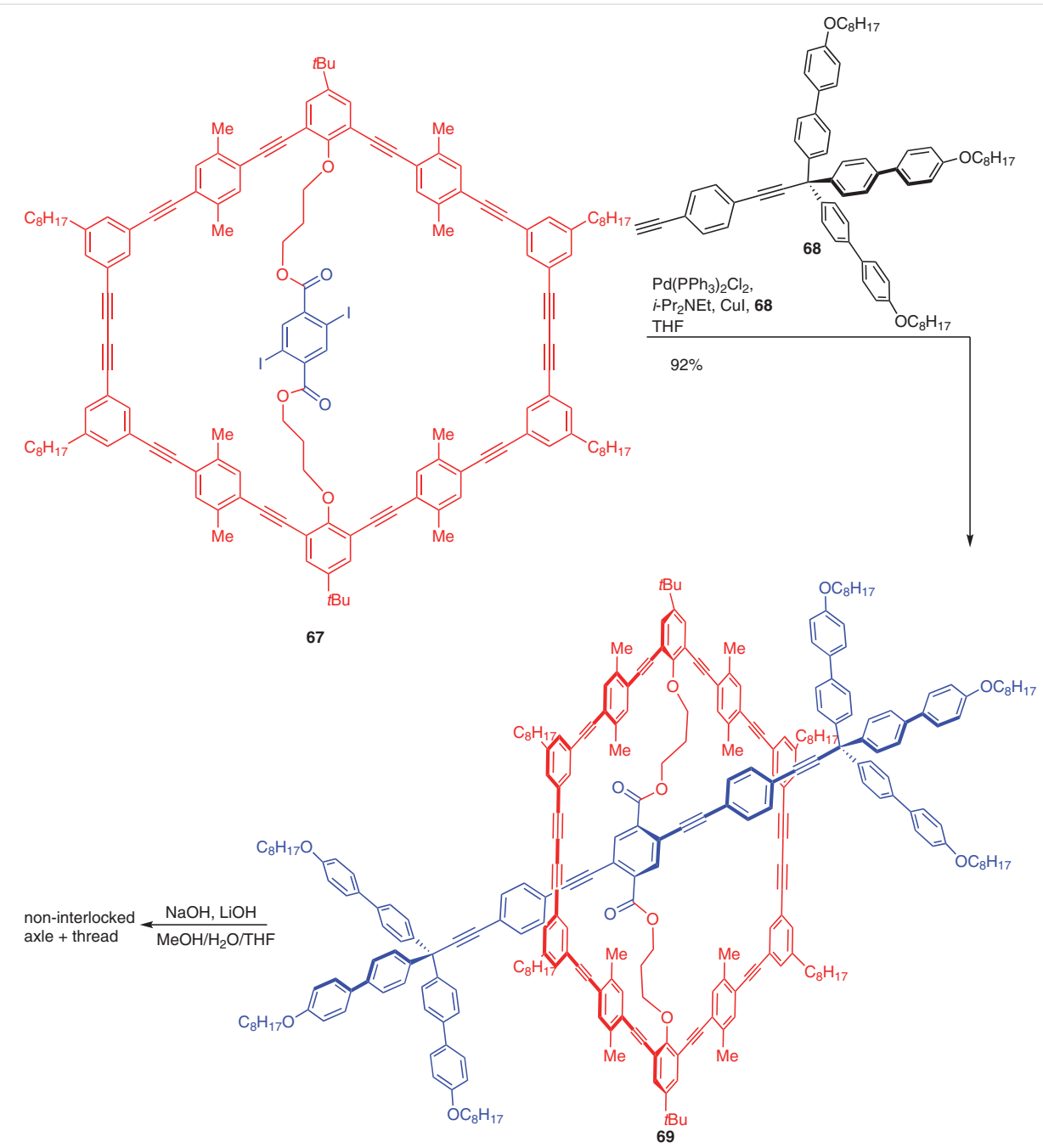

Scheme 17 Morin's attempted rotaxane synthesis using cleavable ester linkages between axle and thread ${ }^{49}$ 

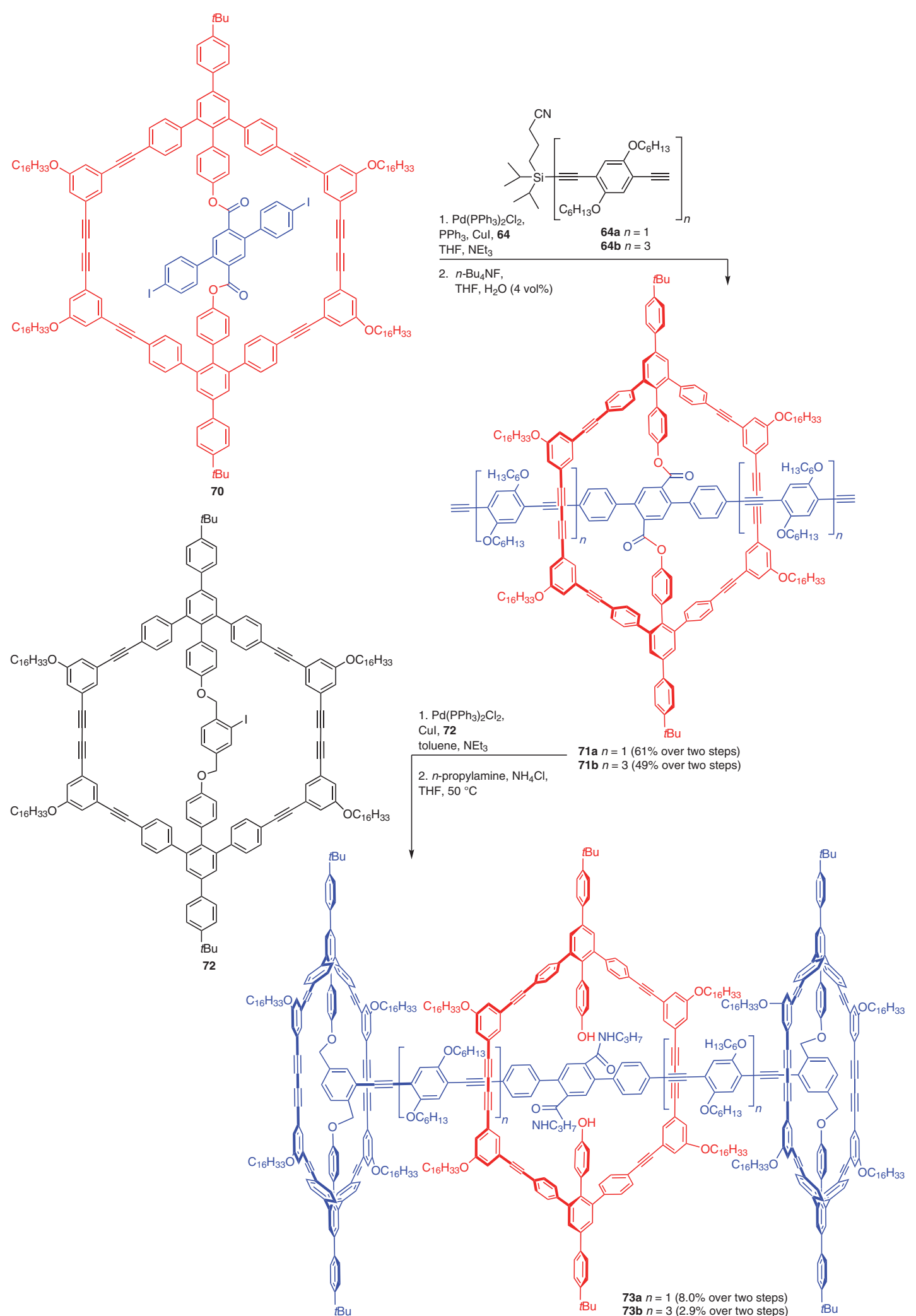

Scheme 18 Höger's synthesis of [2]rotaxanes $\mathbf{7 3 a}$ and $\mathbf{7 3 b}$ using rigid phenylene spacers between axle and terephthalic acid template ${ }^{51}$ 
sistent macrocyclic stoppers as the only explanation for the formation of the decomposition products. This rather puzzling conclusion was supported by molecular mechanics models and a simulation for rare events, demonstrating that the macrocyclic stoppers could bend backwards to give free passage to the central ring. ${ }^{51}$
A catenane, by definition incapable of slipping, was synthesized by Höger through a modified method as illustrated in Scheme 19. ${ }^{52}$ Returning to ring 70, a double Sonogashira coupling with monoprotected ring precursor 74 was performed, after which desilylation produced diyne $\mathbf{7 5}$ in moderate yield. Ring closing was then achieved through a palladium-catalyzed Glaser coupling under pseudo-high dilu-

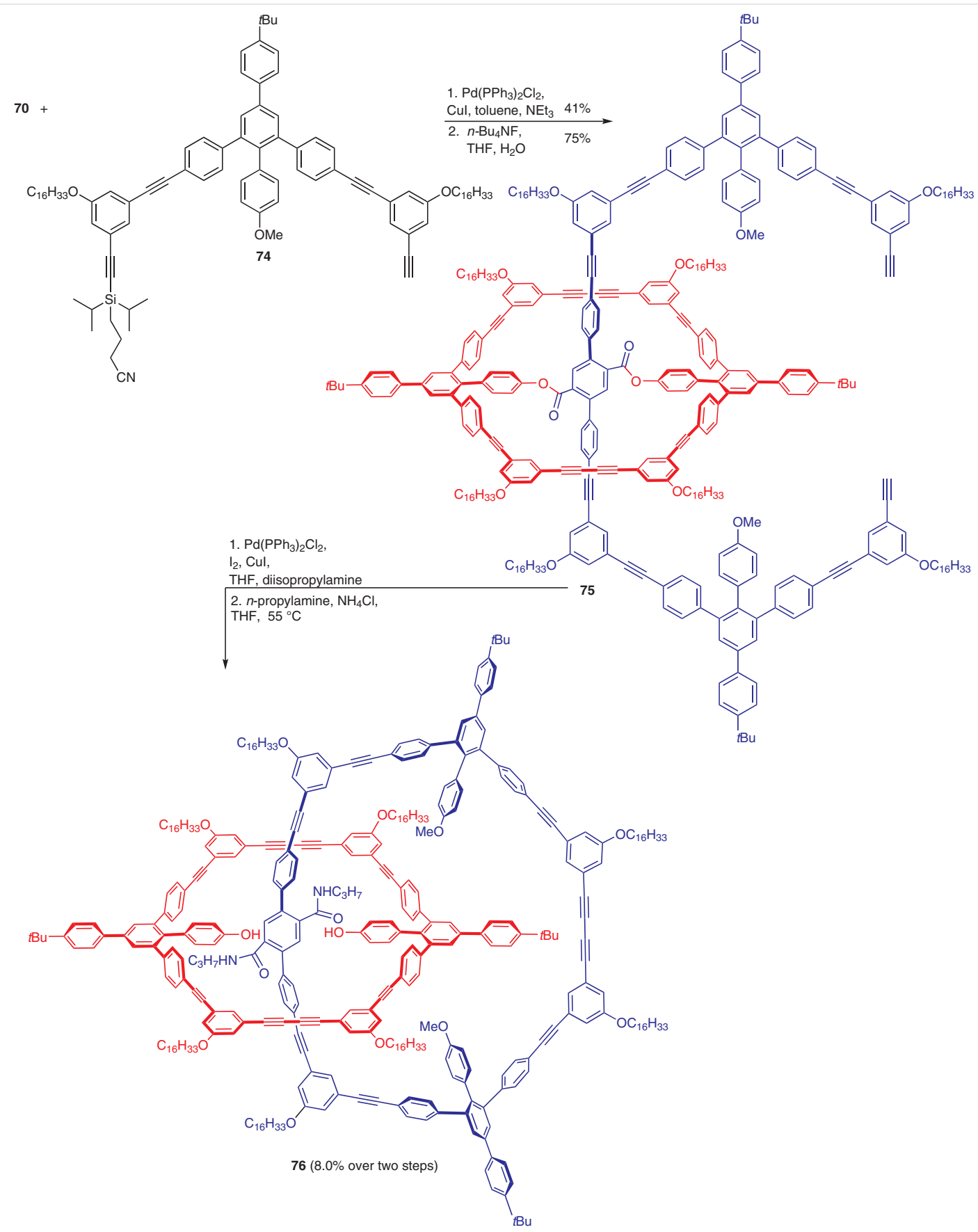

Scheme 19 Höger's synthesis of [2]catenane $\mathbf{7 6}$ by means of aminolysis to cleave the ester linkages ${ }^{52}$ 


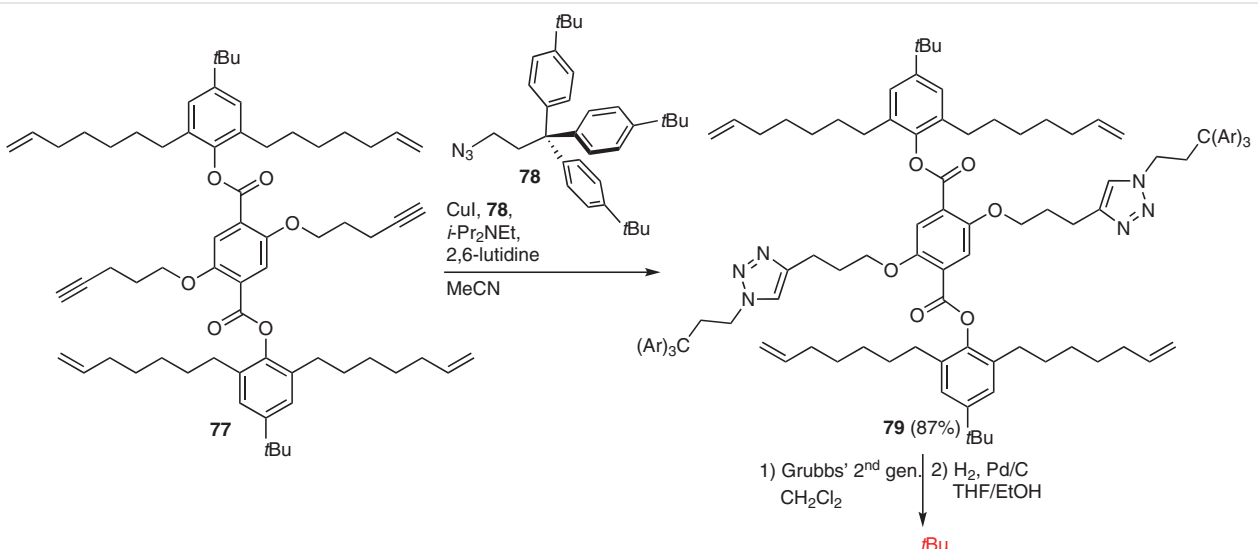

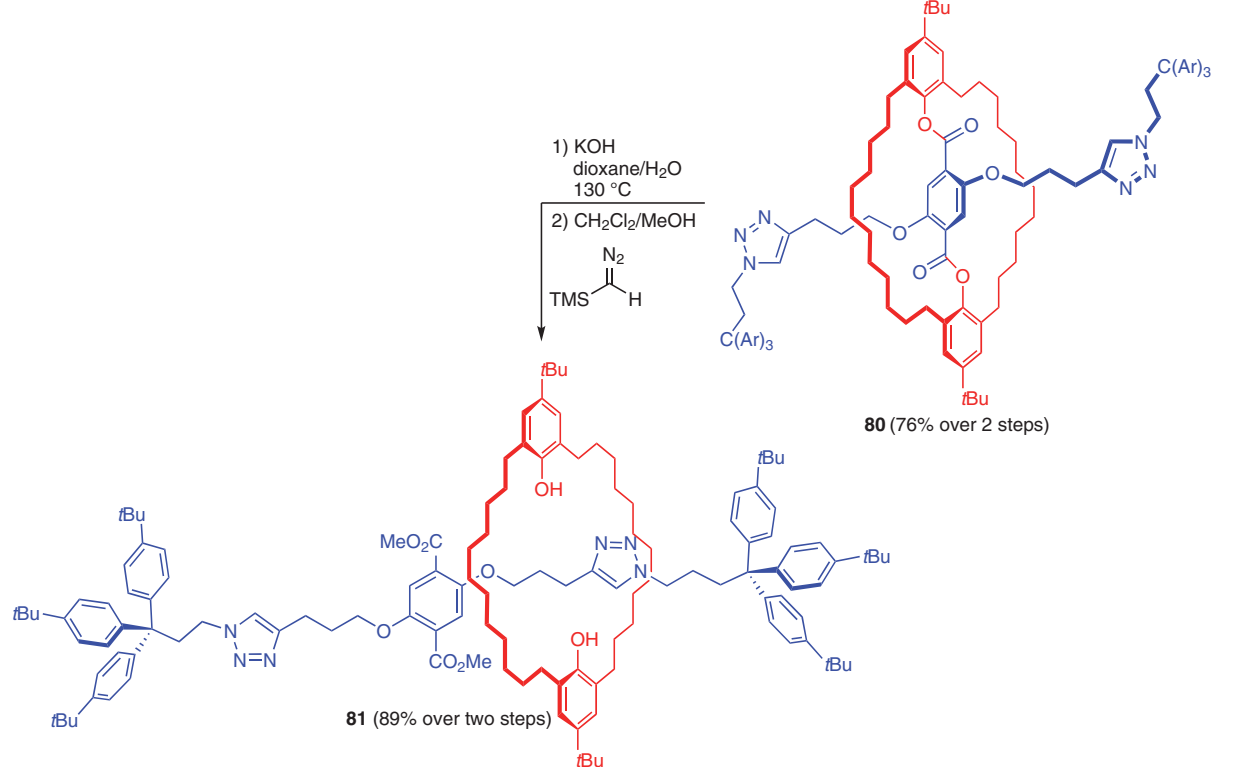

Scheme 20 Synthesis of [2]rotaxane 81 through hydrolysis of the terephthalic acid template as reported by our group ${ }^{53}$

tion to yield a [2]precatenane, as well as small amounts of oligomeric precatenanes (not shown). Aminolysis of the [2]precatenane then resulted in formation of [2]catenane 76 without any signs of free rings in the reaction mixture. Despite the differences in approach, the absence of free macrocycles indicates that this method successfully interlocks the components leading to selective formation of both prerotaxanes and precatenanes. This supports the hypothesis that the synthetic control is derived from the double Sonogashira reaction (e.g., of $\mathbf{7 0}$ and $\mathbf{7 4}$ ), wherein the first coupling shields off one face of the macrocycle and forces the second to occur on the other side. Slippage is consequently the only viable explanation for the decomposition of [2]rotaxane 73a and $\mathbf{7 3 b}$.

Our group has also employed a terephthalic acid template in the synthesis of rotaxanes, as shown in Scheme $20 .^{53}$ Compound $\mathbf{7 7}$ was decorated with acetylene and olefin groups to allow for selective macrocyclization through ring-closing metathesis and modification of the axle via click chemistry.

In this instance, capping was performed first by means of the facile CuAAC reaction with azide stopper $\mathbf{7 8}$ to give tetraene $\mathbf{7 9}$ in high yield. The ring precursors and thread were positioned at a sufficient angle to ensure that metathesis would form the macrocycle around the axle, after which catalytic hydrogenation yielded prerotaxane $\mathbf{8 0}$.

The high yield of the ring-closing metathesis may be attributed to the direct link between ring precursor and template as well as the small ring size, which provides rigidity to enforce the sole formation of the threaded conformer. This was confirmed by DFT calculations, which showed that the threaded conformer is indeed the lowest in energy for this system. Combined with the thermodynamic control of ring-closing metathesis, this led to the selective formation of threaded isomer $\mathbf{8 0}$. An inconvenient consequence of the smaller ring size is the difficult hydrolysis of the ester linkages between axle and ring. The aminolysis conditions as 
used by Höger gave no conversion, ${ }^{51}$ but hydrolysis at high temperature and under high pressure liberated the macrocycle at last. Methylation then provided [2]rotaxane $\mathbf{8 1}$ in excellent yield as no dethreading was observed.

With the aim of preparing higher order rotaxanes, we devised a modular synthesis using the building blocks depicted in Scheme 21.54 Compared to our previous [2]rotaxane synthesis, the key difference is the altered reaction order in which ring-closing metathesis was performed prior to axle assembly.

This gave access to the versatile diols $\mathbf{8 2}, \mathbf{8 5}$, and $\mathbf{8 7}$, which were readily converted into pseudorotaxanes carrying either dialkyne (i.e., 83) or diazide axle fragments (84, $\mathbf{8 6}$, and 88). Subjecting the pseudorotaxanes to CuAAC reactions with 0.4 equivalents of stopper 78, 90, or 91 then selectively yielded mono-stoppered compounds 92-96. As illustrated in Scheme 22, these building blocks were simply clicked together to yield a series of hetero- and homorotaxanes (97-105), containing up to three interlocked rings.
Both axle and macrocycle could be functionalized at a late stage in the synthesis, demonstrating the suitability of this method for the preparation of functional hetero[n]rotaxanes. Prerotaxane $\mathbf{1 0 1}$ was obtained with an elongated axle using linker 89, while dibromo compound 106 was subjected to a Suzuki-Miyaura reaction to give prerotaxane 107. The hydrolysis of [n]rotaxanes was optimized by using Tesser's base (dioxane/MeOH/2 M NaOH), which allowed for cleavage of the ester linkages under milder conditions.

Very recently, we reported a novel synthetic strategy towards catenane and rotaxane products (Scheme 23). ${ }^{55}$ This method is somewhat of a hybrid between our terephthalic acid approach (Schemes 20-22) and templated backfolding strategy (Schemes 5-8). With the distant future goal of synthesizing a lasso peptide, we aimed to include directional components in the mechanically interlocked products. In compound 108 we incorporated a central trisubstituted isophthalate $\delta$-amino acid template (in blue), equivalent to a dipeptide unit with an ester functionalized side chain.

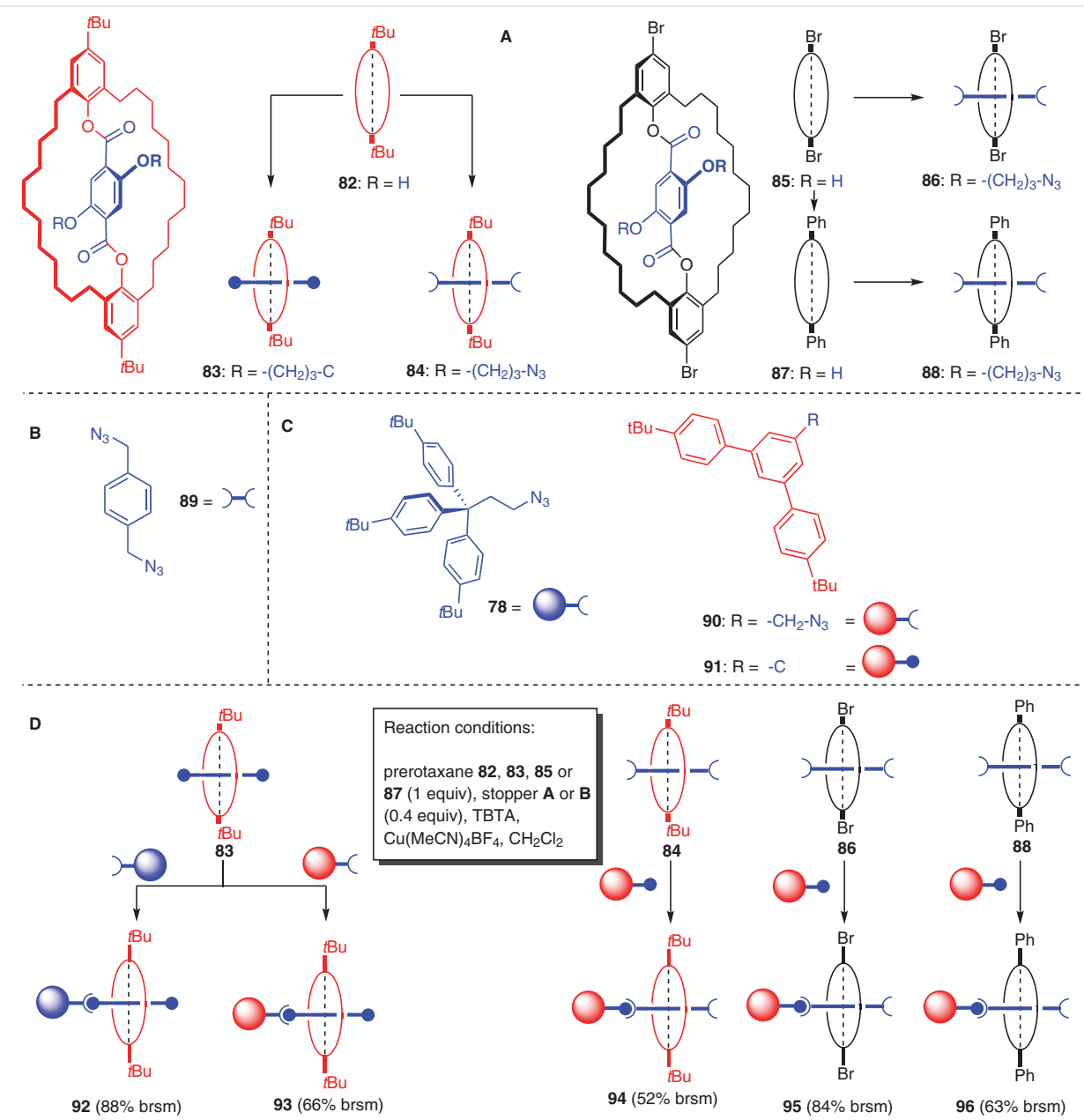

Scheme 21 Preparation of the building blocks for the modular rotaxane synthesis reported by our group. ${ }^{54} \mathbf{A}$ : pseudorotaxanes, B: linker, C: stoppers, D: mono-stoppered pseudorotaxanes. 


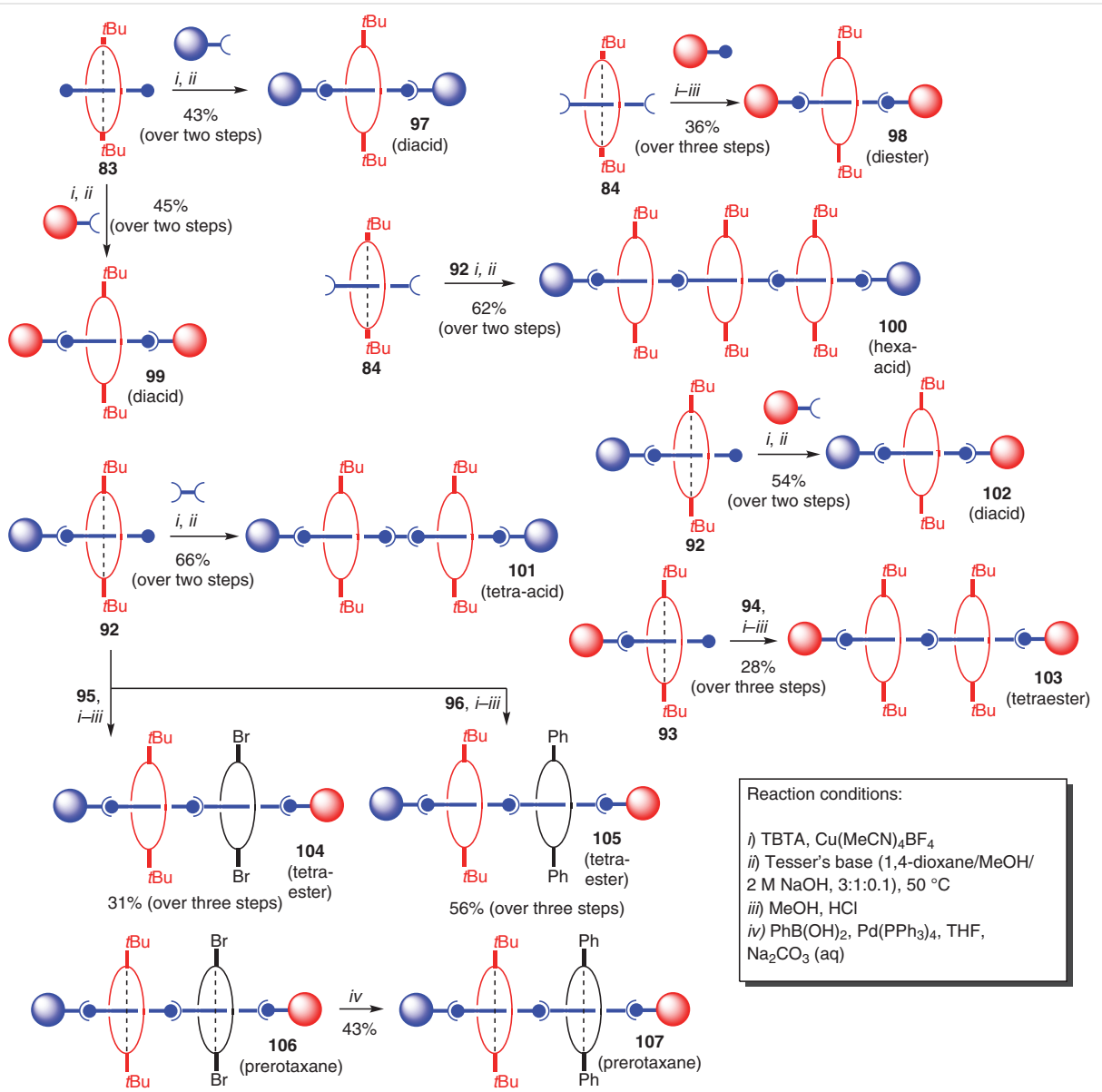

Scheme 22 Modular synthesis of [2]-, [3]-, and [4]rotaxanes using click chemistry to link components and hydrolysis as the final step ${ }^{54}$

The temporary linkages (in black) between the auxiliary (in red) and the amide moieties again serve to position the alkyne/azide pair of ring precursors above and below the directional thread (in blue). A CuAAC reaction hence inevitably folds the ring around the blue thread to give diene $\mathbf{1 0 9}$ in good yield. Cross-metathesis with stopper $\mathbf{2 6}$ then selectively yielded prerotaxane $\mathbf{1 1 0}$.

This prerotaxane was converted into a [2]rotaxane under surprisingly mild transesterification conditions, which cleaved all three ester bonds simultaneously. In an additional step the benzylic tethers were removed under acidic conditions, resulting in [2] rotaxane 111. Notably, the only side products observed in these steps arose from competing cleavage of the benzylic ethers in the red ring.

In an alternative route from diene 109, ring-closing metathesis followed by catalytic hydrogenation afforded precatenane 112. Unfortunately, the ring-closing metathesis reaction did not proceed as smoothly as cross metathesis, which was ascribed to an insufficient length of the olefin side chains. Nonetheless, transesterification of precatenane 112 proved as facile as that of prerotaxane 110, and [2]catenane $\mathbf{1 1 3}$ was obtained in a higher yield after the final step. The relatively small size of the macrocycles in these interlocked products combined with the presence of bulky aromatic components results in interesting co-conformational properties which were revealed by NMR spectroscopy. [2]Rotaxane 111 exists as a mixture of translational isomers with the macrocycle resting on either side of the central template, while [2]catenane $\mathbf{1 1 3}$ is chiral due to hindered pirouetting of the 31-membered macrocycle. ${ }^{55}$ In addition, both possess 'rubber glove' type symmetry inversion emerging from the terephthalic ester moiety. ${ }^{56}$

\section{Conclusion}

The covalently templated syntheses discussed in this review make use of varied macrocyclization reactions and modes of preorganization, hence giving access to MiMs with wide-ranging structures and properties. These approaches have yielded 'impossible' MiMs lacking preorganizing motifs, such as the catenanes comprised of phenylacetylene macrocycles as well as the CPP/CPP catenane, in which the high symmetry of the components was success- 

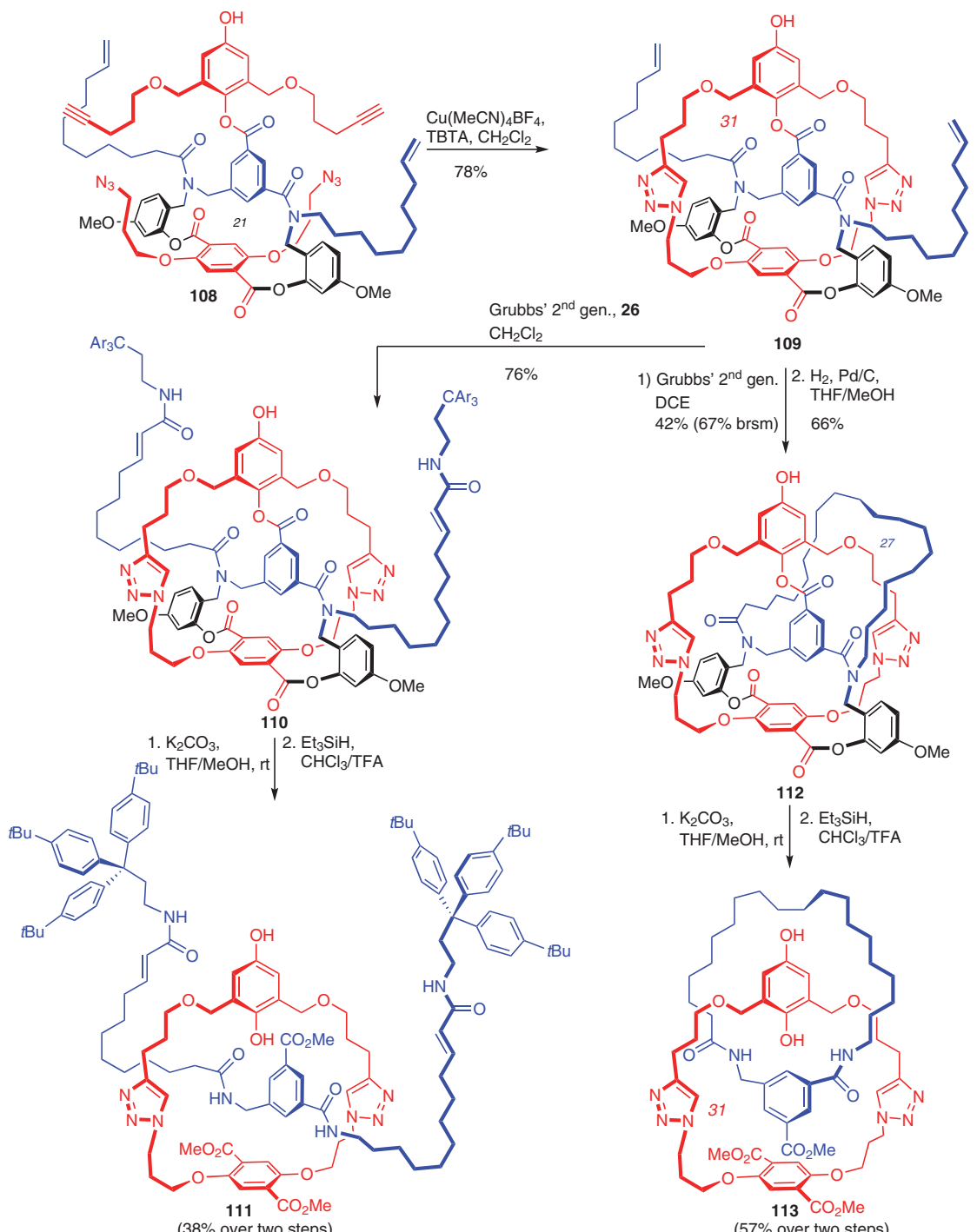

$\mathrm{CH}_{2} \mathrm{Cl}_{2}$

109

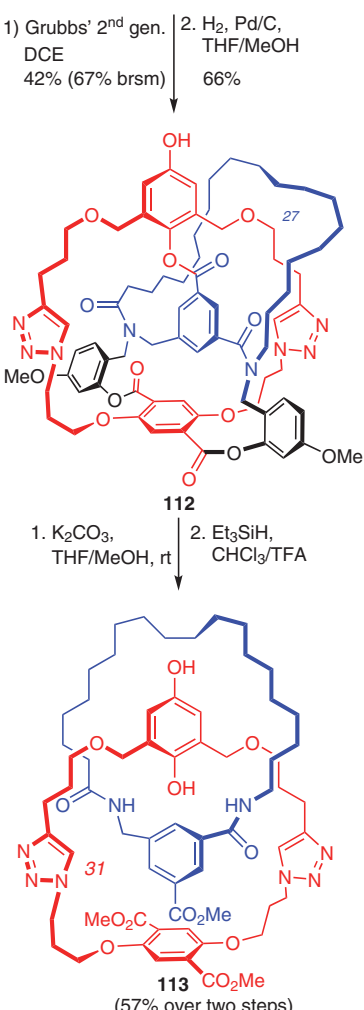

Scheme 23 Synthesis of [2]rotaxane 111 and [2]catenane $\mathbf{1 1 3}$ through a combination of the templated backfolding and terephthalic acid approaches $^{55}$

fully preserved. Moreover, covalently templated syntheses are highly tolerant to structural changes, allowing for finetuning of their properties. This ease of modification is clearly exemplified by the syntheses of the hydrindacenetemplated dynamic covalently linked [2]rotaxanes and the terephthalate-templated modular synthesis of [n]rotaxanes. Further progress is needed to widen the scope of covalent approaches with regard to chiral or stimuli-responsive MiMs. Recent advances in synthetic strategies, such as templated backfolding, are a step in this direction and call for increased attention for covalent approaches. Although the discussed syntheses are generally less efficient than strategies based on non-covalent interactions, we believe that the two approaches have complementary merits. Si- multaneously implementing both methods will create new opportunities in the synthesis of MiMs and accelerate the efforts towards artificial molecular machines and interlocked natural products.

\section{Conflict of Interest}

The authors declare no conflict of interest.

\section{Funding Information}

The authors would like to thank the Nederlandse Organisatie voor Wetenschappelijk Onderzoek (Netherlands Organization for Scientific Research, NWO-CW, ECHO grant number 711.012.007 to J.v.M). 


\section{References}

(1) Bruns, C. J.; Stoddart, J. F. The Nature of the Mechanical Bond: From Molecules to Machines; John Wiley \& Sons: Hoboken, 2017.

(2) Abendroth, J. M.; Bushuyev, O. S.; Weiss, P. S.; Barrett, C. J. ACS Nano 2015, 9, 7746.

(3) Moulin, E.; Faour, L.; Carmona-Vargas, C. C.; Giuseppone, N. Adv. Mater. 2020, 32, 1906036.

(4) Maksimov, M. O.; Pan, S. J.; Link, A. J. Nat. Prod. Rep. 2012, 29, 996.

(5) Taylor, W. R. Nature 2000, 406, 916.

(6) Dean, F. B.; Stasiak, A.; Koller, T.; Cozzarelli, N. R. J. Biol. Chem. 1985, 260, 4975.

(7) Schill, G.; Lüttringhaus, A. Angew. Chem., Int. Ed. Engl. 1964, 3, 546.

(8) Schill, G.; Zollenkopf, H. Justus Liebigs Ann. Chem. 1969, 721, 53.

(9) Rißler, K.; Schill, G.; Fritz, H.; Vetter, W. Angew. Chem., Int. Ed. Engl. 1981, 20, 187.

(10) (a) Schill, G. Catenanes, Rotaxanes and Knots; Academic Press: New York, 1971. (b) Brückner, R. Eur. J. Org. Chem. 2019, 2019, 3289.

(11) Dietrich-Buchecker, C. O.; Sauvage, J.-P.; Kintzinger, J. P. Tetrahedron Lett. 1983, 24, 5095.

(12) Ashton, P. R.; Grognuz, M.; Slawin, A. M. Z.; Stoddart, J. F.; Williams, D. J. Tetrahedron Lett. 1991, 32, 6235

(13) Hunter, C. A. J. Am. Chem. Soc. 1992, 114, 5303.

(14) Aucagne, V.; Hänni, K. D.; Leigh, D. A.; Lusby, P. J.; Walker, D. B. J. Am. Chem. Soc. 2006, 128, 2186.

(15) Ashton, P. R.; Glink, P. T.; Stoddart, J. F.; Tasker, P. A.; White, A. J. P.; Williams, D. J. Chem. Eur. J. 1996, 2, 729.

(16) Li, H.; Fahrenbach, A. C.; Dey, S. K.; Basu, S.; Trabolsi, A.; Zhu, Z.; Botros, Y. Y.; Stoddart, J. F. Angew. Chem. Int. Ed. 2010, 49, 8260.

(17) McConnell, A. J.; Beer, P. D. Chem. Eur. J. 2011, 17, 2724.

(18) Ciaccia, M.; Núñez-Villanueva, D.; Hunter, C. A. J. Am. Chem. Soc. 2019, 141, 10862.

(19) (a) Nierengarten, I.; Meichsner, E.; Holler, M.; Pieper, P.; Deschenaux, R.; Delavaux-Nicot, B.; Nierengarten, J.-F. Chem. Eur. J. 2018, 24, 169. (b) Nierengarten, I.; Nierengarten, J.-F. ChemistryOpen 2020, 9, 393. (c) Rémy, M.; Nierengarten, I.; Park, B.; Holler, M.; Hahn, U.; Nierengarten, J.-F. Chem. Eur. J. 2021, 27, 8492 .

(20) Lancia, F.; Ryabchun, A.; Katsonis, N. Nat. Rev. Chem. 2019, 3 , 536.

(21) Perutz, M. F. Nature 1970, 228, 726.

(22) Ünsal, Ö.; Godt, A. Chem. Eur. J. 1999, 5, 1728.

(23) Duda, S.; Godt, A. Eur. J. Org. Chem. 2003, 2003, 3412.

(24) Godt, A. Eur. J. Org. Chem. 2004, 2004, 1639.

(25) Sauvage, J. P. Acc. Chem. Res. 1990, 23, 319.

(26) Godt, A.; Duda, S.; Ünsal, Ö.; Thiel, J.; Härter, A.; Roos, M.; Tschierske, C.; Diele, S. Chem. Eur. J. 2002, 8, 5094.

(27) Shah, R. S.; Duda, S.; Müller, B.; Godt, A.; Malik, A. J. Am. Chem. Soc. 2003, 125, 5408.

(28) Schill, G.; Schweickert, N.; Fritz, H.; Vetter, W. Angew. Chem., Int. Ed. Engl. 1983, 22, 889.
(29) Segawa, Y.; Kuwayama, M.; Hijikata, Y.; Fushimi, M.; Nishihara, T.; Pirillo, J.; Shirasaki, J.; Kubota, N.; Itami, K. Science 2019, 365, 272.

(30) Segawa, Y.; Kuwayama, M.; Itami, K. Org. Lett. 2020, 22, 1067.

(31) Jasti, R.; Bhattacharjee, J.; Neaton, J. B.; Bertozzi, C. R. J. Am. Chem. Soc. 2008, 130, 17646.

(32) Steemers, L.; Wanner, M. J.; Lutz, M.; Hiemstra, H.; van Maarseveen, J. H. Nat. Commun. 2017, 8, 15392.

(33) Wanner, M. J.; Steemers, L.; Uiterweerd, M. T.; Klijn, R. S.; Ehlers, A. W.; van Maarseveen, J. H. Chem. Eur. J. 2018, 24, 13114.

(34) Schill, G.; Beckmann, W.; Vetter, W. Chem. Ber. 1980, 113, 941.

(35) Steemers, L.; Wanner, M. J.; van Leeuwen, B. R. C.; Hiemstra, H.; van Maarseveen, J. H. Eur. J. Org. Chem. 2018, 2018, 874.

(36) Pilon, S.; Jørgensen, S. I.; van Maarseveen, J. H. Chem. Eur. J. 2021, 27, 2310.

(37) Hiratani, K.; Suga, J. I.; Nagawa, Y.; Houjou, H.; Tokuhisa, H.; Numata, M.; Watanabe, K. Tetrahedron Lett. 2002, 43, 5747.

(38) Nagawa, Y.; Fukazawa, N.; Suga, J. I.; Horn, M.; Tokuhisa, H.; Hiratani, K.; Watanabe, K. Tetrahedron Lett. 2000, 41, 9261.

(39) Kameta, N.; Hiratani, K.; Nagawa, Y. Chem. Commun. 2004, 466.

(40) Hiratani, K.; Kaneyama, M.; Nagawa, Y.; Koyama, E.; Kanesato, M. J. Am. Chem. Soc. 2004, 126, 13568.

(41) Nagawa, Y.; Suga, J. I.; Hiratani, K.; Koyama, E.; Kanesato, M. Chem. Commun. 2005, 749.

(42) Kawai, H.; Umehara, T.; Fujiwara, K.; Tsuji, T.; Suzuki, T. Angew. Chem. Int. Ed. 2006, 45, 4281.

(43) Kawai, H. Bull. Chem. Soc. Jpn. 2015, 88, 399.

(44) Kawai, H.; Katoono, R.; Fujiwara, K.; Tsuji, T.; Suzuki, T. Chem. Eur. J. 2005, 11, 815.

(45) Umehara, T.; Kawai, H.; Fujiwara, K.; Suzuki, T. J. Am. Chem. Soc. 2008, 130, 13981.

(46) Sugino, H.; Kawai, H.; Umehara, T.; Fujiwara, K.; Suzuki, T. Chem. Eur. J. 2012, 18, 13722.

(47) Höger, S.; Meckenstock, A.-D.; Pellen, H. J. Org. Chem. 1997, 62, 4556.

(48) Becker, K.; Lagoudakis, P. G.; Gaefke, G.; Höger, S.; Lupton, J. M. Angew. Chem. Int. Ed. 2007, 46, 3450.

(49) Cantin, K.; Lafleur-Lambert, A.; Dufour, P.; Morin, J.-F. Eur. J. Org. Chem. 2012, 2012, 5335.

(50) Fischer, M.; Höger, S. Tetrahedron 2003, 59, 9441.

(51) Schweez, C.; Shushkov, P.; Grimme, S.; Höger, S. Angew. Chem. Int. Ed. 2016, 55, 3328.

(52) Schweez, C.; Höger, S. Chem. Eur. J. 2018, 24, 12006.

(53) Steemers, L.; Wanner, M. J.; Ehlers, A. W.; Hiemstra, H.; van Maarseveen, J. H. Org. Lett. 2017, 19, 2342.

(54) Cornelissen, M. D.; Pilon, S.; Steemers, L.; Wanner, M. J.; Frölke, S.; Zuidinga, E.; Jørgensen, S. I.; van der Vlugt, J. I.; van Maarseveen, J. H. J. Org. Chem. 2020, 85, 3146.

(55) Pilon, S.; Jørgensen, S. I.; van Maarseveen, J. H. ACS Org. Inorg. Au 2021, in press DOI: https://doi.org/10.1021/acsorginorgau.1c00017.

(56) Chambron, J.-C.; Sauvage, J.-P.; Mislow, K.; De Cian, A.; Fischer, J. A. Chem. Eur. J. 2001, 7, 4085. 